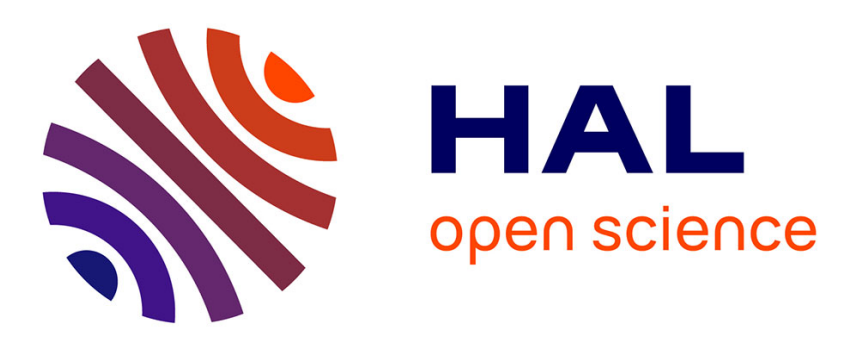

\title{
Seismic Dispersion and Attenuation in Fluid-Saturated Carbonate Rocks: Effect of Microstructure and Pressure
}

\author{
Jan Borgomano, Lucas Pimienta, Jérôme Fortin, Yves Gueguen
}

\section{To cite this version:}

Jan Borgomano, Lucas Pimienta, Jérôme Fortin, Yves Gueguen. Seismic Dispersion and Attenuation in Fluid-Saturated Carbonate Rocks: Effect of Microstructure and Pressure. Journal of Geophysical Research : Solid Earth, 2019, 10.1029/2019JB018434 . hal-02567562

\section{HAL Id: hal-02567562 \\ https://hal.science/hal-02567562}

Submitted on 7 May 2020

HAL is a multi-disciplinary open access archive for the deposit and dissemination of scientific research documents, whether they are published or not. The documents may come from teaching and research institutions in France or abroad, or from public or private research centers.
L'archive ouverte pluridisciplinaire HAL, est destinée au dépôt et à la diffusion de documents scientifiques de niveau recherche, publiés ou non, émanant des établissements d'enseignement et de recherche français ou étrangers, des laboratoires publics ou privés. 


\section{JGR Solid Earth}

Correspondence to: Jan V. M. Borgomano, borgomano@geologie.ens.fr

Citation:

Borgomano, J. V. M., Pimienta, L. X., Fortin, J. N., \& Gueguen, Y. (2019). Seismic dispersion and attenuation in fluid-saturated carbonate rocks: Effect of microstructure and pressure. Journal of Geophysical Research: Solid Earth, 124, 12,498-12,522.

https://doi.org/10.1029/2019JB018434

Received 24 JUL 2019

Accepted 15 NOV 2019

Accepted article online 23 NOV 2019

Published online 5 DEC 2019

CC2019. American Geophysical Union. All Rights Reserved.

\section{Seismic Dispersion and Attenuation in Fluid-Saturated Carbonate Rocks: Effect of Microstructure and Pressure}

\author{
Jan V. M. Borgomano1 ${ }^{(1 D}$, Lucas X. Pimienta ${ }^{1,2}$ iD , Jérôme Fortin $^{1}$, and Yves Guéguen ${ }^{1}$ \\ ${ }^{1}$ Laboratoire de Géologie de l'ENS-UMR8538-CNRS, PSL Research University, Paris, France, ${ }^{2}$ Laboratory of \\ Experimental Rock Mechanics, École Polytechnique Fédérale de Lausanne, Lausanne, Switzerland
}

\begin{abstract}
The frequency dependence of seismic properties of fully saturated rocks can be related to wave-induced fluid flows at different scales. The elastic dispersion and attenuation of four fluid-saturated carbonate rocks, with different microstructures, have been measured over a broad frequency range in the laboratory. The selected rocks were a presalt coquina from offshore Congo, an Urgonian limestone from Provence (France), and an Indiana limestone either intact or thermally cracked. The selected samples present a variety of pore types characteristic of carbonates, and their link with potential squirt flow dispersion was investigated. To cover a broad frequency range, forced oscillations $(0.004 \mathrm{Ho} 100 \mathrm{~Hz})$ and ultrasonic $(1 \mathrm{MHz})$ measurement techniques were performed in a triaxial cell, at various differential pressures, on the samples saturated by fluids of different viscosity. Both hydrostatic and axial oscillations were applied in order to get the different dynamic moduli. For all our samples, the drained/undrained transition and the squirt flow mechanisms were characterized experimentally, in terms of amplitude of dispersion, amount of viscoelastic attenuation, and frequency ranges. Biot-Gassmann's theory was found to apply mainly at seismic frequencies $(10-100 \mathrm{~Hz})$. A potential correlation between pore type and possible squirt flow dispersion was investigated. Intragranular microporosity, with either a rimmed or uniform distribution, does not seem to generate any substantial dispersion. On the other hand, cracked intergranular cement and uncemented grain contacts seem to generate substantial squirt flow dispersion, at respectively seismic and sonic log frequencies.
\end{abstract}

\section{Introduction}

Geophysical exploration with seismic methods or sonic logs measurements are essential to estimate the nature of the subsurface. They are extensively used in oilfields exploration and monitoring, as the seismic wave velocities are strongly sensitive to the critical parameters of the reservoir rock, such as porosity, lithofacies, saturation, pore fluid nature, or pressure. However, the link between seismic velocity and these rock parameters is complex and has been the main focus of the research in rock physics (Avseth et al., 2005).

The frequency dependence (dispersion) of the $P$ and $S$ wave velocities raises questions on how to compare low-frequency field measurements $(\sim[20 ; 100] \mathrm{Hz}$ for seismic data; $\sim 10 \mathrm{kHz}$ for well logs) to conventional high-frequency ultrasonic measurements in the laboratory $(1 \mathrm{MHz})$. Moreover, the related attenuation $\left(Q^{-1}\right)$ may be detected in the frequency spectrum of seismic traces, for example, through instantaneous spectral analysis technique (Castagna et al., 2003; Odebeatu et al., 2006), and may give insight on the presence of hydrocarbon or gas saturation in a reservoir. Hydrocarbon deposits are often associated with higher attenuation, which should be considered in amplitude-versus-offset analysis. Chapman et al. (2006), for example, showed that attenuation may induce frequency-dependent reflector coefficients that can be detected in synthetic stacked data and interpreted in terms of squirt flow dispersion. Monopole and dipole waveform well $\log$ data are also a means to measure respectively $P$ and $S$ wave attenuation (Cheng et al., 1982; Cheng et al., 1984; Sun \& Frazer, 2000) in the field. However, attenuation obtained from well data are generally greater than from seismic data, which may be attributed to microbedding or to the frequency dependence of $Q^{-1}$ (e.g., Frazer et al., 1997).

At frequencies low enough (below Biot's frequency), poroelasticity theory is a linear viscoelastic theory (Sidler et al., 2013; Solazzi et al., 2016). In the absence of scattering or inertial effects (Biot, 1956), the dispersion of the elastic wave velocities in fully saturated rocks is mainly related to viscous-driven fluid flows 
occurring at different scales in the rock porosity (Batzle et al., 2006; Müller et al., 2010; Sarout, 2012). However, the underlying mechanisms and their magnitudes may vary greatly depending on the rocks and their microstructures, which requires dedicated measurements of the low-frequency moduli in the laboratory. Numerous studies investigated fully saturated sandstones (e.g., Spencer, 1981; Winkler, 1985; Paffenholz \& Burkhardt, 1989; David et al., 2013; Madonna \& Tisato, 2013; Mikhaltsevitch et al., 2014; Subramaniyan et al., 2015; Subramaniyan et al., 2017; Tisato et al., 2015; Pimienta et al., 2015a; 2015b; Spencer \& Shine, 2016; Chapman et al., 2016; Yin et al., 2017; Yin et al., 2019), but only few investigated the microstructurally complex and variable carbonate rocks (e.g., Spencer, 1981; Batzle et al., 2006; Adam et al., 2006; Adam et al., 2009; Mikhaltsevitch et al., 2016a; Borgomano et al., 2017), although they represent more than $60 \%$ of the reservoir rocks for hydrocarbons.

If the dry properties of the rock are known, the standard procedure to estimate the fluid-saturated properties is Biot-Gassmann's fluid substitution theory (Gassmann, 1951). However, Biot-Gassmann's relation is only valid at low frequencies, where the pore pressure is equilibrated at the scale of the representative elementary volume (REV) (Rice \& Cleary, 1976). Studies from Mavko and Nur (1975), O'Connell and Budiansky (1977) or Mavko and Jizba (1991), for example, showed that microscale wave-induced pressure gradients are possible at higher frequencies (Mavko et al., 2009). This phenomenon is referred to as the squirt flow mechanism. Biot-Gassmann's isobaric assumption is therefore violated, and the high-frequency wave velocities of saturated rocks are greater than expected (Adelinet et al., 2010; Dvorkin et al., 1995; O'Connell \& Budiansky, 1977). Two other dissipation mechanisms could occur at even higher frequencies: (i) scattering, which is excluded here as occurring from wave propagation, and (ii) inertial effects accounted for in Biot's theory (Biot, 1956), which are also excluded as this mechanism occurs at frequencies much higher than the ones studied here (e.g., Sarout, 2012).

The recent laboratory measurements of Pimienta et al. (2015a, 2015b, 2017) or Chapman et al. (2019) are examples of experimental evidences that the elastic properties of fully saturated sandstones depend on frequency. Three distinct fluid-flow regimes can be considered (O'Connell \& Budiansky, 1978): (i) drained, (ii) undrained (REV saturated isobaric), and (iii) unrelaxed (REV saturated nonisobaric). Two transitions are expected between these three regimes. The first transition (drained/undrained) is related to the global pore fluid pressure relaxation along the sample due to the pore lines, and the second transition (undrained/unrelaxed) is related to local flows occurring within the REV of the sample. Although such local flows could have different origins, such as crack-to-pore flow, flow out of grain contacts, or in general, flow between pore types of contrasting compressibility, we regroup them under the generic term of "squirt flow" (Dvorkin et al., 1995). At sufficiently high frequencies, the squirt flow may not have time to relax the pressure gradients within the REV, leading to the unrelaxed regime where all the inclusions act as if they were isolated (unconnected). The drained/undrained transition is mainly controlled by the sample's macroscopic parameters (such as the bulk modulus, the ratio between rock permeability, and fluid viscosity) and the sample's size and permeability. The undrained/unrelaxed transition is mainly controlled by macroscopic parameters (such as the bulk modulus and fluid viscosity) and microscopic parameters (such as the mean crack aspect ratio in the case of crack-to-pore squirt flow).

Carbonate rocks are characterized by complex microstructures and heterogeneous pore types (Lucia, 1995). For a given porosity, carbonate rocks were shown to exhibit a wide range of $P$ wave and $S$ wave velocities, due to the large variety of pore types (Eberli et al., 2003). Their elastic properties are affected by the pore network and the mineralogy, which can be modified through diagenetic processes (Fournier \& Borgomano, 2009; Regnet et al., 2018). Most of the predictive models for squirt flow (e.g., Gurevich et al., 2010) require the knowledge of parameters such as crack aspect ratio or crack density. Generally, these parameters are unaccessible from field measurements, and we cannot predict if dispersion is affecting the wave propagations. Presenting an approach that goes from the geology and pore types toward potential dispersion may prove to be more effective for field interpretation.

Several studies have attempted to understand the relationship between seismic wave velocity and porosity (e.g., Anselmetti \& Eberli, 1993; Verwer et al., 2010) or to verify the applicability of Biot-Gassmann's fluid substitution theory (e.g., Baechle et al., 2009; Bemer et al., 2016; Fabricius et al., 2010). All these studies are based on ultrasonic measurements, and little is known on how those properties could change over the frequency range and might affect either seismic or sonic logs measurements in the field. The study from Fabricius et al. (2010) gives a first insight on the link between depositional texture and dispersion. 
The heterogeneous packstones or dolomites with uncertain depositional textures seem to be more susceptible to be dispersive compared to mudstones or grainstones (Fabricius et al., 2010), but it remains unclear which specific pore type might trigger such dispersion and which frequency and effective pressure ranges it would affect. Moreover, very few experiments monitored the evolution of all the elastic moduli during these dispersive transitions (e.g., Borgomano et al., 2017).

Because of the variety of pore types inherent to carbonates, it is still unclear if wave-induced fluid flow may induce dispersion and attenuation of the wave velocities and if seismic, logs, or ultrasonic measurements may be affected. To study the effect of different pore types on the dispersion and attenuation of the dynamic moduli, we investigated four calcite-pure limestones presenting very different microstructures, over a large frequency range $(0.01-100 \mathrm{~Hz})$. We used forced oscillations and ultrasonic velocities under a differential pressure up to $30 \mathrm{MPa}$. Two samples may be relevant for either Brazil or East Arabic plate reservoirs. The other two samples are from a limestone quarry in Indiana (United States). The Indiana limestone has been measured intact and after thermal cracking. The elastic dispersion and attenuation are first measured and interpreted in terms of existing models. They are then used to compute the $P$ and $S$ wave velocity dispersion and attenuation across the investigated frequency range to have an overview of the potential bias when comparing routine laboratory ultrasonics with field measurements.

\section{Methodology}

\subsection{Experimental Apparatus}

The new Top Industrie cell (Figure 1) at Ecole Normale Supérieure de Paris is an autonomous (integrated piston) and autocompensated cell, which can reach $100 \mathrm{MPa}$ of confining pressure. The apparatus is equipped with six single-screw pumps controlling the axial load, the confining pressure, and the pore fluid pressures (two for glycerin and two for water) in the upper and lower inlets (Figure 1).

The sample plug, of height $80 \mathrm{~mm}$ and diameter $40 \mathrm{~mm}$, is held between two end platens and is laterally isolated from the confining oil by a neoprene jacket (Figure 1). The top and bottom end platens are drilled to allow injecting and controlling the pore pressure from the top and the bottom of the sample. Moreover, they are both equipped with $P$ and $S$ ultrasonic transducers of $10 \mathrm{~mm}$ diameter and $1 \mathrm{~mm}$ height from PI Ceramic (type PIC255/ref PRYY+0.111) to measure ultrasonic velocities across the sample's length. The lower end platen is made out of aluminum 2017A (AU4G) and is equipped with four axial strain gauges that are used to measure the axial stress (Figure 1).

The apparatus setup uses two integrated pore pressure pumps filled with water, each of $200 \mathrm{ml}$ volume, and an additional Quizix QX-1500 dual-pump of $50 \mathrm{ml}$ volume, filled with glycerin, connected to the drainage circuit. The top and bottom drainage circuits can be closed by two valves near the end platens, which creates small dead volumes of about $3.3 \mathrm{ml}$ each at the top and bottom of the sample (Figure 1). In order to achieve nearly pure drained boundary conditions, these valves were kept opened so that the dead volumes are large and equal to the volume of the connected pumps. Pimienta, Borgomano, et al. (2016) showed that a dead volume greater than 10 times the pore space volume of the sample would induce a difference of less than $2 \mathrm{GPa}$ between the measured and the real drained bulk modulus. These pumps were also used to measure permeability using the steady state flow rate method (Darcy flow).

The cell has 37 electrical wires output on which a total of 14 foil strain gauges (TML FCB-6-350-11) in quarter-bridge configuration can be connected. The sample's strain gauges are glued at midheight on the lateral surface. Up to four pairs of axial/radial strain gauges were glued on each sample. The lower end platen is made out of aluminum 2017A and is equipped with four axial strain gauges that play the role of axial stress sensors (Figure 1). The maximum sampling rate of the data acquisition system is $4 \mathrm{kHz}$, which can be selected according to the frequency of the stress oscillations to reduce the size of the data files. A Labview software controls both the pumps and the data acquisition. The confining pump can be programmed through a sequencer that enables to perform tasks, say a sequence of different frequencies, automatically.

When the piston is not in contact with the axial column, the confining pressure pump can perform pure hydrostatic oscillations around a mean value, with a maximum frequency of $1.2 \mathrm{~Hz}$. To perform axial oscillations, the piston is lowered in contact with the column, in which a PICA piezoelectric stack actuator from PI Ceramic (P-050-20) is mounted just above the top end platen. It enables to generate axial-stress oscillations up to $100 \mathrm{~Hz}$ (Figure 1). The blocking pressure of the piezo actuator is around $35 \mathrm{MPa}$. When applying axial oscillations, a small deviatoric stress of $1 \mathrm{MPa}$ is applied by the piston to prestress the piezoelectric oscillator. The electrical input of the actuator is controlled by a TTi TG1010A function generator further amplified by high-power amplifier. 


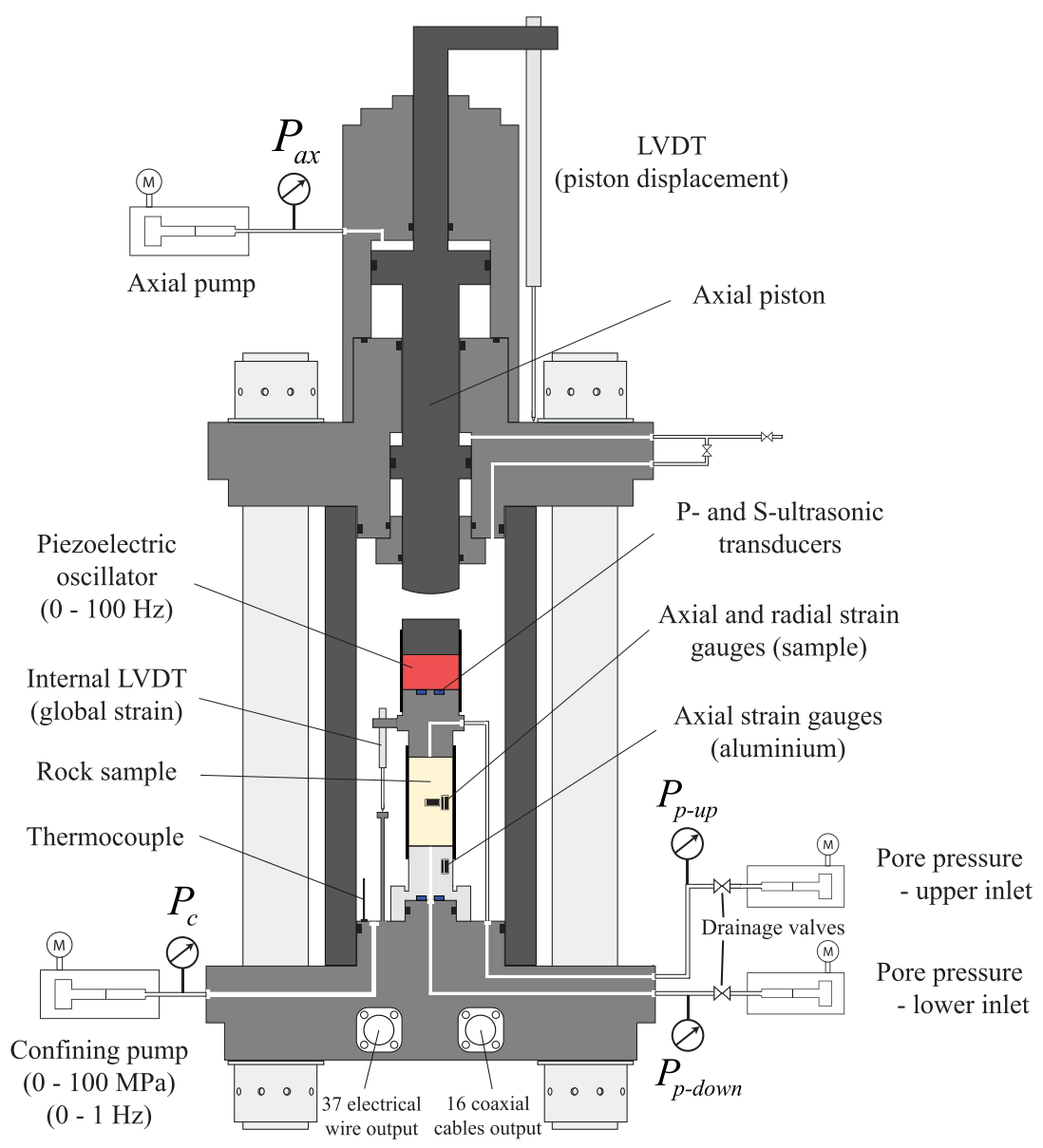

Figure 1. Schematic diagram of the experimental apparatus. The hydrostatic oscillations are generated by the confining pressure pump and the axial oscillations by the piezoelectric actuator. $P$ and $S$ ultrasonic transducers are installed in the top and bottom endplatens. Drained boundary conditions can be achieved by leaving the drainage valves open to the pumps to create large pressurized dead volumes for the pore fluid.

\subsection{Forced-Oscillations Method}

\subsubsection{Dispersion and Attenuation Measurement}

We use in the following the framework of linear viscoelasticity. To measure the dispersion and the attenuation of the dynamic moduli over a large frequency range, we used two methods: (i) the forced oscillation method (e.g., Batzle et al., 2006; Adelinet et al., 2010; Jackson et al., 2011; Tisato \& Madonna, 2012; David et al., 2013; Mikhaltsevitch et al., 2014; Pimienta et al., 2015b; Chapman et al., 2016; Szewczyk et al., 2016; Sun et al., 2018) and (ii) ultrasonic measurements. In order to be in the linear elastic domain for both types of oscillations, the stress amplitudes are adjusted so that the amplitudes of the strains are around $10^{-6}$.

The hydrostatic stress oscillations $(\Delta P)$ induce a volumetric strain $\varepsilon_{v o l}$, from which we can get the bulk modulus by

$$
K_{h y d}=\frac{-\Delta P_{c}}{\varepsilon_{v o l}} .
$$

Note that the use of " $K_{\text {hyd }}$ " means that the bulk modulus is inferred from hydrostatic oscillations.

The Young's modulus and Poisson's ratio can be obtained from the axial oscillations by

$$
E=\frac{\sigma_{a x}}{\varepsilon_{a x}} \text { and } \quad v=-\frac{\varepsilon_{r a d}}{\varepsilon_{a x}},
$$

where $\varepsilon_{a x}$ and $\varepsilon_{r a d}$ are the average of all the axial and radial strains respectively, and $\sigma_{a x}=E_{a l u} \varepsilon_{a l u}$, where $E_{a l u}$ and $\varepsilon_{\text {alu }}$ are, respectively, the Young's modulus and average axial strain of the aluminum lower end platen. 
With the assumption of isotropic medium, a bulk modulus $K_{a x}$ and a shear modulus $G$ can be calculated from the real parts of $E$ and $v$. Note again that the use of " $K_{a x}$ " means that the bulk modulus is inferred from axial oscillations. In an elastic isotropic medium, we expect $K_{h y d}=K_{a x}$ if experimental errors are small enough.

Attenuation is usually quantified by the inverse of the quality factor $Q^{-1}$. In viscoelasticity, $Q^{-1}$ measures the dissipated elastic energy during an oscillation cycle. For a complex elastic modulus $\bar{M}$, the calculation of the $Q_{M}^{-1}$ factor is given by (O'Connell \& Budiansky, 1978)

$$
Q_{M}^{-1}=\frac{\operatorname{Im}(\bar{M})}{\operatorname{Re}(\bar{M})}=\frac{\operatorname{Im}(\bar{\sigma} / \bar{\varepsilon})}{\operatorname{Re}(\bar{\sigma} / \bar{\varepsilon})}=\tan \left(\varphi_{\sigma}-\varphi_{\varepsilon}\right),
$$

where the complex modulus $\bar{M}$ relates the stress $\bar{\sigma}$ to its resulting strain $\bar{\varepsilon}$ by $\bar{\sigma}=\bar{M} \bar{\varepsilon}$. In our case, $\bar{M}$ can be $\bar{K}$ (bulk modulus), $\bar{E}$ (Young's modulus), of $\bar{G}$ (shear modulus). ( $\varphi_{\sigma}-\varphi_{\varepsilon}$ ) is the phase shift between the applied stress and the strain response. Poisson's ratio can as well be defined as a complex quantity. An analog calculation can be done as $Q_{v}^{-1}=\tan \left(\varphi_{\varepsilon_{r a d}}-\varphi_{\varepsilon_{a x}}\right)$, where $\left(\varphi_{\varepsilon_{r a d}}-\varphi_{\varepsilon_{a x}}\right)$ is the phase shift between radial and axial strains, although Poisson's ratio is not an elastic modulus so that $Q_{v}^{-1}$ cannot really be considered as an attenuation factor. Fourier transform was used on all the stress and strain recordings to pick amplitudes and phases.

The uncertainties associated with the dynamic moduli can be computed from the uncertainty on the strain averages used. For each frequency, a standard deviation based on a two-sided Student's $t$ distribution with a confidence of $60 \%$ is evaluated, which takes into account the number of strain gauges. For one modulus, we then give the largest relative uncertainty observed for the various effective pressures and saturating fluids used.

\subsubsection{Frequency Range and Fluid Nature}

With the current apparatus, similar calibrations as done by Pimienta et al. (2015a, 2015b) have shown that the maximum frequencies reachable with hydrostatic and axial oscillations are 1.2 and $100 \mathrm{~Hz}$, respectively. One can modify the apparent frequency range of the diffusion mechanisms related to viscous fluid flows by changing the viscosity of the saturating fluid (e.g., Batzle et al., 2006). This only works for Newtonian fluids and if the fluid-flow mechanisms at play are solely viscous driven and not inertial, that is, in the quasi-static domain of poroelasticity (Biot, 1956). Biot's theory of poroelasticity accounted for inertial effects, occurring when the frequency is high enough to suppress the viscous coupling between the solid and the fluid. Biot's frequency $f_{b}$ is a frequency threshold that separates the quasi-static and the dynamic domain of poroelasticity, given by (Mavko et al., 2009)

$$
f_{b}=\frac{\eta_{f l} \phi}{2 \pi D_{f l} \kappa}
$$

where $D_{f l}$ is the density of the fluid. The lowest-frequency limit below $f_{b}$ corresponds to the Gassmann limit (Gassmann, 1951). We verify later that the measurements are all within the quasi-static domain of poroelasticity by calculating $f_{b}$ for each sample (Table 1 ).

The samples were measured under dry and glycerin- and water-saturated conditions. The glycerin used for the experiments is the Glycerol $\geq 98 \%$ GPR RECTAPUR provided by VWR Chemicals. At room temperature $\left(20{ }^{\circ} \mathrm{C}\right)$, the viscosity of glycerin and water are $\eta_{g l y}=1 \mathrm{~Pa} \cdot \mathrm{s}$ and $\eta_{w a t}=10^{-3} \mathrm{~Pa} \cdot \mathrm{s}$, respectively. If $f<f_{b}$, the use of glycerin viscosity enables to increase the so-called "apparent frequency range" $\left(f^{*}=f \times \eta / \eta_{w a t}\right)$ of the measurements by about 3 orders of magnitude, using water as a reference. This allows to observe in laboratory, the elastic behavior of water-saturated rocks at equivalent well log frequencies $(10 \mathrm{kHz})(\mathrm{e} . \mathrm{g}$., Pimienta et al., 2015a; Borgomano et al., 2017). Since glycerin is very soluble in water, the samples were first measured dry, then were measured with glycerin- and, finally, in water-saturated conditions. Before being jacketed and installed into the cell, the samples were dried in a humidity-free oven at $80^{\circ} \mathrm{C}$ for at least 1 day.

To fully saturate the rock with glycerin after the dry measurements, a vacuum is generated from the top side of the sample. Once the vacuum propagated completely to the bottom side (monitored by the two pressure transducers $P_{p-u p}$ and $P_{p-\text { down }}$ visible in Figure 1), the fluid is injected from the bottom side ( $P_{p-u p}$ still being vacuum), at a pressure around $2 \mathrm{MPa}$. Once the fluid has invaded the sample and the pressure buildup is detected at the top side $\left(P_{p-u p}\right)$, the upper inlet is opened to atmosphere to evacuate any residual bubbles. Before closing back the tubing, the sample is flushed with a volume of glycerin at least equal to twice the 
Table 1

Properties of the Coquina, Rustrel, and Indiana (Intact and Thermally Cracked) Samples

\begin{tabular}{|c|c|c|c|c|}
\hline Samples & Coquina & Rustrel & Indiana intact & Indiana thermally cracked \\
\hline Porosity, $\Phi(\%)$ & 7.5 & 14.9 & 11.4 & 13.9 \\
\hline Permeability, $\kappa\left(\mathrm{m}^{2}\right)$ & $5 \times 10^{-17}$ & $4 \times 10^{-17}$ & $2 \times 10^{-17}$ & $3 \times 10^{-17}$ \\
\hline Crack density, $\rho$ & 1.3 & 0.5 & 0.2 & 1.0 \\
\hline Characteristic crack aspect ratio, $\xi$ & $2.75 \times 10^{-4}$ & $1.84 \times 10^{-4}$ & $1.76 \times 10^{-4}$ & $1.44 \times 10^{-4}$ \\
\hline Crack porosity, $\phi_{c}(\%)$ & 0.15 & 0.04 & 0.02 & 0.06 \\
\hline High-pressure bulk modulus, $K_{h}(\mathrm{GPa})$ & 30 & 26 & 34 & 23 \\
\hline Skeleton bulk modulus, $K_{S}(\mathrm{GPa})$ & 77 & 77 & 77 & 77 \\
\hline Drained/undrained cutoff frequency, $f_{1}^{*}(\mathrm{~Hz})$ & 0.16 & 0.36 & 0.25 & 0.1 \\
\hline Squirt flow cutoff frequency, $f_{2}^{*}(\mathrm{~Hz})$ & 1600 & 477 & 420 & 230 \\
\hline Biot dynamic cutoff frequency, $f_{b}(\mathrm{~Hz})$ & $2.4 \times 10^{8}$ & $5.9 \times 10^{8}$ & $9.1 \times 10^{8}$ & $6.1 \times 10^{8}$ \\
\hline
\end{tabular}

Note. Except for the high-pressure bulk modulus $\left(K_{h}\right)$, all the properties are given for an effective pressure of $2.5 \mathrm{MPa}$. The permeability was measured by steady state fluid flow under water saturation. The characteristic crack density $\rho$ and crack aspect ratio $\xi$ are determined by Morlier's method (Morlier, 1971), after fitting an exponential function in the pressure dependence of $K$ in dry conditions where $K_{h}$ corresponds to the high-end asymptotic value above 30 MPa pressure. The crack porosity is calculated by $\phi_{c}=4 / 3 \pi \rho \xi$ (Adelinet et al., 2011). The drained/undrained $\left(f_{1}^{*}\right)$, squirt flow $\left(f_{2}^{*}\right)$, and Biot $\left(f_{b}\right)$ cutoff frequencies are calculated for water-saturated conditions.

sample's porosity to ensure proper saturation. The injected volume can be accurately monitored with the pore pressure pump.

After the glycerin measurements, an other set of pore pressure pumps, filled with water, is connected to the cell. As before, the upper tubing is opened to atmosphere to allow the glycerin to be flushed out while water is injected from the bottom of the sample. The pore fluid exiting the sample can be controlled from this outlet, and the flushing is stopped when pure water is detected. In general, a water volume of about 2 to 3 times the porosity is flushed through the sample to ensure that the glycerin is completely dissolved and evacuated.

\section{Carbonate Samples}

In this study, we selected calcite-pure $(\geq 97 \%)$ carbonates which have different microstructures and pore types. Mineralogy is verified through energy dispersive X-ray (EDX) analysis. The selected samples were a coquina limestone from an offshore well, an outcrop limestone from Rustrel (France), and an Indiana limestone that was measured intact and after thermal cracking. Scanning electron microscopy (SEM) photomicrographs and mercury-injection capillary-pressure (MICP) analysis of the samples are presented in Figure 2. The sample's parameters are resumed in Table 1. Porosity was measured by triple-weight method, and permeability was measured in the triaxial cell using steady flow rate method (darcy flow) at an effective pressure of $2.5 \mathrm{MPa}$.

\subsection{Presalt Coquina From Offshore Congo}

The coquina sample measured here is a grainstone originating from a deep well in offshore Republic of Congo, around $60 \mathrm{~km}$ off the West African Atlantic Margin, in the presalt sequence at least at $4 \mathrm{~km}$ depth. Coquinas are detrital rocks that are mainly composed of calcitic shell debris. They can also be composed with a large amount of siliciclastic or other carbonate components such as pellets (Thompson et al., 2015). Few experimental studies on coquinas have been published because of the limited availability of well-cores (e.g., Regnet et al., 2018).

In the South Atlantic, number of offshore hydrocarbon reservoirs are presalt lacustrine carbonates, and more specifically coquinas. These coquina reservoirs are located in the Brazilian and West African continental margins, and were deposited on shallow lacustrine platforms created during the breakup of West Gondwana in the Early Cretaceous (Thompson et al., 2015). The Congo-Angola margin is a passive continental margin that resulted from the opening of the South Atlantic Ocean in the Early Cretaceous (Marton et al., 2000). Three main units can be distinguished in the sedimentary series of the lower Congo basin, which are related to three tectonic phases: prerift continental deposits (Jurassic), synrift fluviolacustrine deposits and sag phase (Lower Cretaceous), and postrift unit with large accumulation of salt (Middle Aptian) covered 
Reflected light photomicrographs

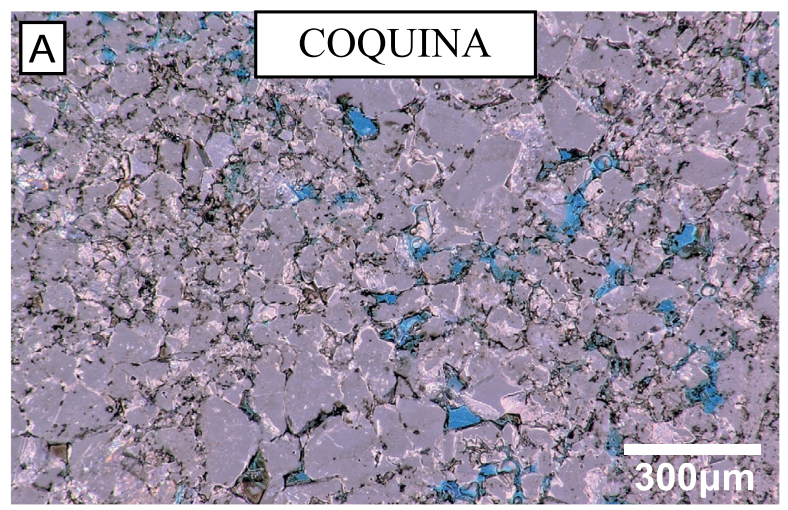

SEM photomicrographs

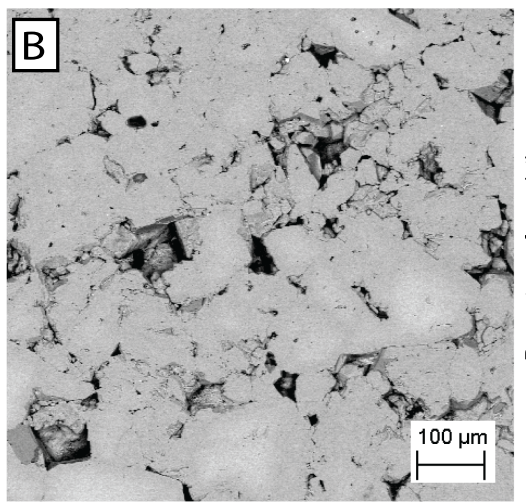

Mercury injection capillary pressure analysis
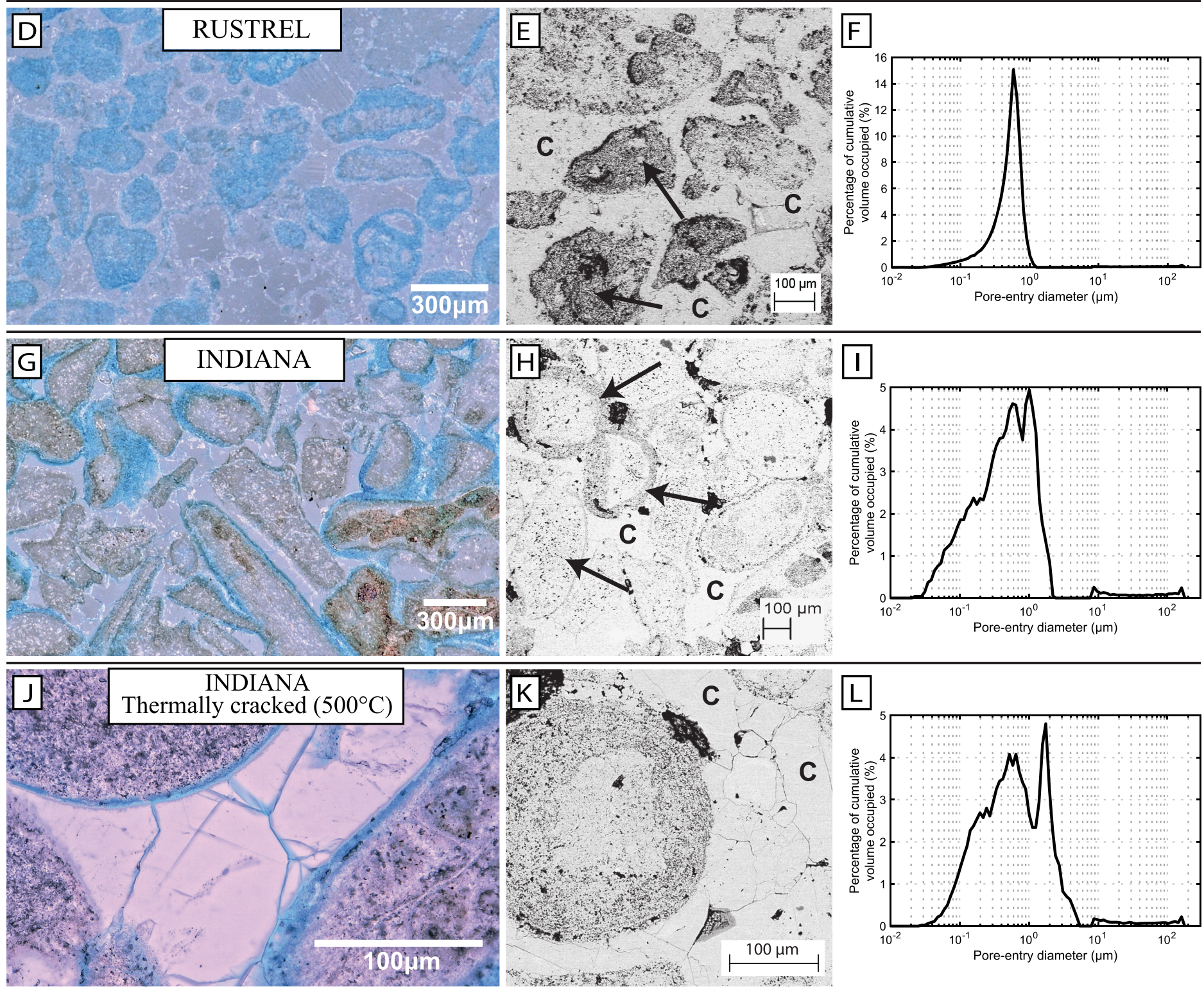

Figure 2. Thin sections under reflected light microscope, SEM photomicrographs and pore entry diameters from mercury injection capillary pressure (MICP) analysis of the coquina (respectively a, b, c), Rustrel (respectively d, e, f), intact Indiana (respectively g, h, i), and thermally cracked Indiana (respectively j, k, l) samples. The porosity is saturated with a blue colorant in the thin sections. The arrows indicate zones of intragranular microporosity, and $C$ indicates intergranular calcitic cement. 
by thick marine successions (Albian to present) (Savoye et al., 2009). The margin hosts one of the largest deep-sea fan in the world, with a maximum thickness of $5 \mathrm{~km}$ (Anderson et al., 2000), which bears important activity in terms of sedimentary processes due to active turbidity currents (Wonham et al., 2010). Oligocene and Miocene turbidite systems are particularly studied by the oil industry due to oil and gas reservoirs discoveries in the Tertiary series (Savoye et al., 2009). Beneath the fan, there is the Middle-Aptian Salt (Loeme Formation) that covers the Lower-Cretaceous lacustrine deposits (Wonham et al., 2010), from which our sample originates. The presalt coquinas of this latter deposits are of major interest as they could be analogs to the presalt lacustrine deposites of the Brazilian offshore fields, although the deposition conditions were slightly different. The west african coquinas deposited on distally steepened ramps and rimmed platforms, whereas the Brazilian coquinas were deposited on low angle ramps, resulting in different facies (Thompson et al., 2015).

Reflected light microscope and SEM photomicrographs of the sample are presented in Figures 2a and $2 \mathrm{~b}$. This sample does not bear any large clasts or large moldic pores as frequently observed for coquinas. The texture of our selected plug was homogeneous and fine-grained and seemed to have undergone substantial compaction. The homogeneous matrix is mainly constituted of what seems to be abraded and heavily compacted fragments of shells, with grains less than $100 \mu \mathrm{m}$ that are poorly sorted (Figures $2 \mathrm{a}$ and $2 \mathrm{~b}$ ). These grains do not seem micritized at all and do not bear much microporosity. Some areas seem to have accommodated the compaction through pressure solution with the presence of microstylolites.

The microstructure seems poorly cemented, with intergranular or intercrystalline porosity and very few moldic pores. The EDX analysis showed that the sample is mainly composed of calcite (>97\%). Some traces of quartz and solid bitumen were also detected $(<1 \%)$. The porosity was measured to be around $7.5 \%$, and the dry mass density is around $D_{d r y}=2,540 \mathrm{~kg} / \mathrm{m}^{3}$. The water permeability at $P_{\text {eff }}=2.5 \mathrm{MPa}$ was measured around $5 \times 10^{-17} \mathrm{~m}^{2}$.

The mercury injection capillary pressure (MICP) results show a large distribution of pore entry diameters, with a relatively constant plateau between 0.5 and $5 \mu \mathrm{m}$ (Figure 2c), which could correlate both with intercrystalline microporosity and intergranular porosity in grain contacts. Moreover, a small peak is visible around $10 \mu \mathrm{m}$ that decreases slowly up to $30 \mu \mathrm{m}$ (Figure $2 \mathrm{c}$ ), which should correlate with the intergranular pore space.

\subsection{Rudist-dominated Limestone From Rustrel (France)}

The studied sample comes from a lower cretaceous carbonate platform outcrop in SE of France, corresponding to the barremian-lower Aptian succession in the Monts de Vaucluse (Léonide et al., 2012), which is part of the Urgonian Limestone Formation. The sample was cored in a block that came from Rustrel, in an outcrop identified as "Les Antennes" $\left(43.926516^{\circ} \mathrm{N}, 5.502709^{\circ} \mathrm{E}\right)$ in the studies of Léonide et al. (2012) and Léonide et al. (2014). The corresponding facies is identified as the Rudist facies (FA6) in the studies of Léonide et al. (2012) and Fournier et al. (2014).

The Urgonian limestones from Monts de Vaucluse (Provence, France) give us the opportunity to study close analogs to carbonate reservoir rocks on the east part of the Arabian plate, such as the Kharaib and Shu'aiba Formations (Alsharhan \& Nairn, 1997; Léonide et al., 2012). The depositional context of the Barremian lower Aptian carbonate platform of Provence was very similar to the East Arabic carbonate platform. Therefore, the outcrop limestones are found to be good analogs in terms of age, facies, or reservoir properties (Borgomano et al., 2002; Borgomano et al., 2013; Fournier et al., 2011). The latter studies show the evolution of wave velocities with diagenetic evolution of the pore space, with three main categories: by increasing stiffness (1) purely microporous, (2) preserved intergranular and moldic, and (3) vuggy (Fournier et al., 2014). A large data set of ultrasonic wave velocities has been obtained by Fournier et al. (2014) and showed some substantial dependence to confining pressure for the more compliant intercrystalline micropores, whereas the moldic pores were stiff and less sensible to pressure. To study frequency effects and potential squirt flow related to relative compliant porosities, we selected a sample mainly microporous, with pressure-dependent elastic properties.

The selected facies presented some sparsely distributed rudists of around $1 \mathrm{~cm}$ size. The use of $5 \mathrm{~mm}$ strain gauges prohibits us to measure the strain of such large heterogeneities. We therefore cored the plug in a fine-grained homogeneous part of the block is representative of the matrix surrounding the large rudists. The sample is a grainstone in which the observed grains or pelloides are possibly fragments of larger rudist's 
shell that are extremely micritized (Figures $2 \mathrm{~d}$ and $2 \mathrm{e}$ ). The sample is essentially microporous, with the micropores located in the grains. We do not observe any macropores, as the intergranular pore space is completely filled by calcitic cement. The sample is homogeneous, with poorly sorted grains of maximum size $500 \mu \mathrm{m}$. Therefore, the principal pore types are intragranular micropores within the micritic grains, and some intercrystalline pores within the calcitic cement.

The porosity was measured to be around $14.9 \%$, and the permeability was measured to be around $4 \times 10^{-17} \mathrm{~m}^{2}$ at $P_{\text {eff }}=2.5 \mathrm{MPa}$. The dry density is around $D=2,345 \mathrm{~kg} / \mathrm{m}^{3}$. The MICP results show a clear unimodal pore entry size distribution with a maximum peak at $0.6 \mu \mathrm{m}$ (Figure 2f), which should correspond to the intragranular microporosity.

\subsection{Bioclastic Limestone From Indiana}

The Indiana limestone is a pure calcite bioclastic limestone that comes from Bedford, Indiana, of Mississippian age. It may also be known as the Salem or Spergen limestone (Fossum et al., 1995). Its mechanical properties have been extensively studied in the literature (Brace \& Riley, 1972; Michalopoulos \& Triandafilidis, 1976; Hart \& Wang, 1995; Vajdova et al., 2004; Zhu et al., 2010; Ji et al., 2012).

The sample bears some microporosity within the grains, and very few macropores (Figures $2 \mathrm{~g}$ and $2 \mathrm{~h}$ ). It is essentially composed of fossil fragments and ooids. The distribution of micropores in the some grains, such as oolites, is uniform, while in the majority of the bioclasts the distribution of micropores is rimmed. The intergranular pore space is nearly entirely filled with a homogeneous calcite cement (Figures $2 \mathrm{~g}$ and $2 \mathrm{~h}$ ), in which we did not observe visible cracks. Therefore, it is mainly characterized by some intragranular microporosity, with some intergranular macroporosity. According to Fossum et al. (1995), the calcite distribution is about $69 \%$ of fossiliferous calcite and $31 \%$ of cement calcite, which seems consistent with the photomicrograph of our own sample. The grain sizes can go up to $300 \mu \mathrm{m}$ and are poorly sorted. The total porosity of our sample was estimated around $11.4 \%$ and the permeability was estimated to be around $2 \times 10^{-17} \mathrm{~m}^{2}$ at $P_{\text {eff }}=2.5 \mathrm{MPa}$.

After the sample elastic moduli dispersion and attenuation have been fully studied over the frequency range, the same sample has been thermally cracked in an oven, following the procedure described by Johnston and Toksöz (1980). The temperature was progressively increased to $500^{\circ}$ and was maintained for $1 \mathrm{hr}$ in order to leave sufficient time for outgassing. According to Rodriguez-Navarro et al. (2009), from measurements done on Iceland spar single crystals, the thermal decomposition of calcite $\left(\mathrm{CaCO}_{3}\right)$ into calcium oxide $(\mathrm{CaO})$ and carbon dioxide $\left(\mathrm{CO}_{2}\right)$ starts around $600^{\circ}$ with a very low degree of conversion, and is complete after $850^{\circ}$. Therefore, we assume that our thermally cracked sample has no change in mineralogy. The sample was then naturally cooled down to room temperature and reinstrumented with new strain gauges. From new microscope observations (Figures $2 \mathrm{j}$ and $2 \mathrm{k}$ ), we observed that the induced cracks were essentially located in the intergranular cement. The new porosity was measured around $13.9 \%$, and the permeability was measured to be fairly equivalent to the intact one at about $3 \times 10^{-17} \mathrm{~m}^{2}$. This suggests that the new cracks do not significantly affect the effective hydraulic conductivity of the sample, which seems mainly controlled by the microporosity.

For both the intact and the thermally cracked sample, MICP results exhibit a unimodal pore entry size distribution, with a maximum peak around $0.5 \mu \mathrm{m}$ that corresponds to the microporosity (Figures $2 \mathrm{i}$ and 21). The MICP measurements of the intact sample were actually done on a second core of the similar block as it is a destructive method. The macropores visible in the photomicrographs are not detected by the MICP analysis suggesting that they do not constitute an independent connected network. In other words, the fluid accesses the macropores solely by going through micropores or cracks. The results on the thermally cracked sample are fairly close to the intact one, although there seems to be slightly higher pore entry diameters (Figure 21), with a higher total volume injected. Although the porosity increase could partially be due to the new population of cracks, it is likely that the majority of it may be explained by connecting some previously unconnected porosity.

\section{Dispersion and Attenuation Results}

The sample's are assumed to be isotropic for the calculation of the moduli, and we verify that axial and radial strains are consistent during hydrostatic oscillations. The low-frequency axial and hydrostatic oscillations presented in this section were performed with large dead volumes $(200 \mathrm{ml}$ for the water- and $50 \mathrm{ml}$ for the 


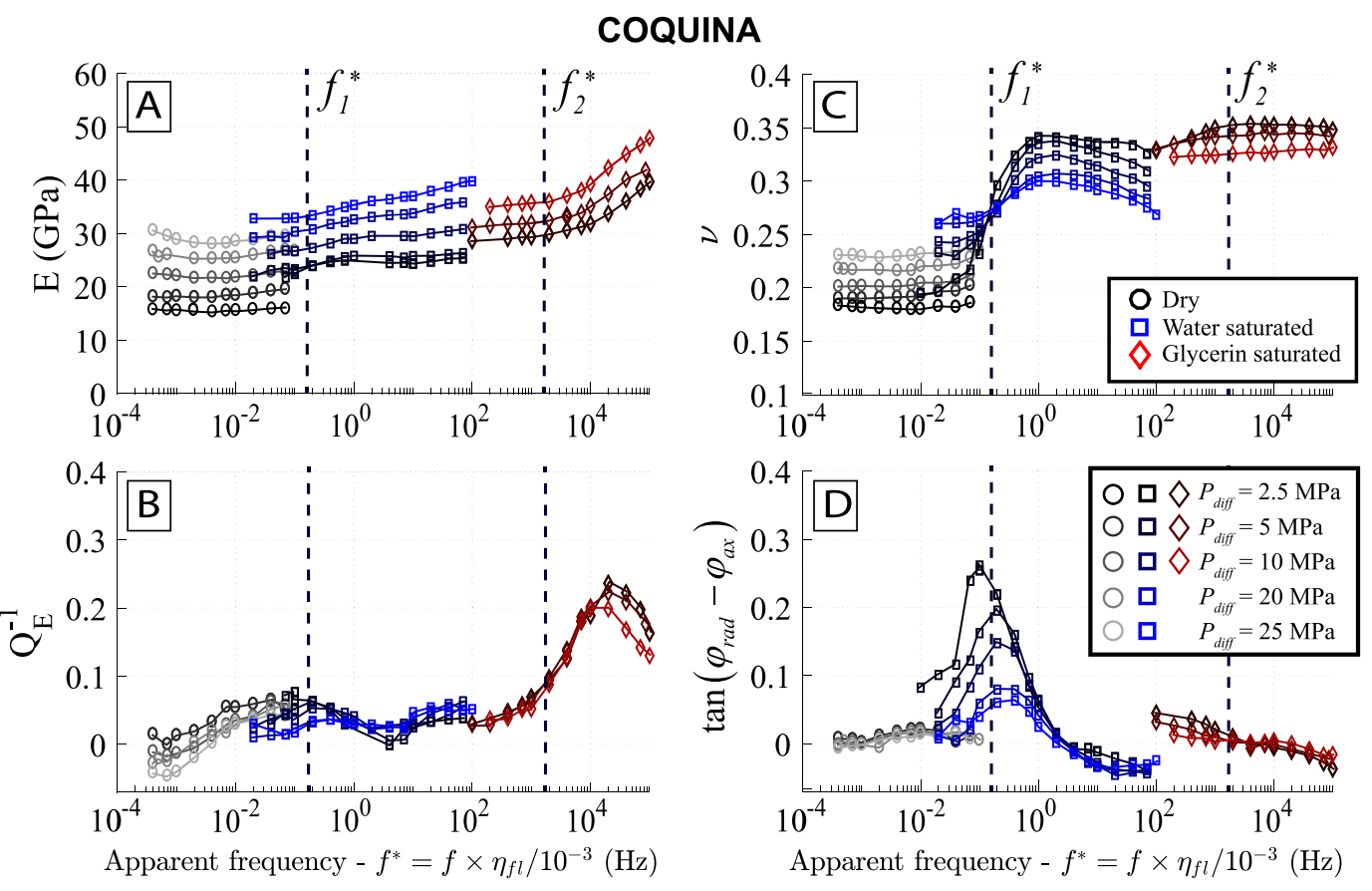

Figure 3. Results of Young's modulus dispersion (a) and attenuation (b), and Poisson's ratio dispersion (c) and related phase shift $\tan \left(\varphi_{\text {rad }}-\varphi_{a x}\right)$ (d) obtained from axial oscillations at differential pressures on the fully saturated coquina sample. Frequency is scaled by the viscosity of the fluid $\left(\eta_{\text {air }}=10^{-5} \mathrm{~Pa} \cdot \mathrm{s}, \eta_{\text {wat }}=10^{-3} \mathrm{~Pa} \cdot \mathrm{s}, \eta_{g l y}=1 \mathrm{~Pa} \cdot \mathrm{s}\right)$, with water taken as reference. The predicted cutoff frequencies for the drained/undrained and possible squirt flow transitions are represented by $f_{1}^{*}$ and $f_{2}^{*}$, respectively.

glycerin-filled pumps) to achieve drained boundary conditions, for different differential pressures $\left(P_{\text {diff }}=\right.$ $\left.P_{c}-P_{p}\right)$ in dry and water- and glycerin-saturated conditions. The pore pressure $\left(P_{p}\right)$ was set to $2 \mathrm{MPa}$, and the confining pressure $\left(P_{c}\right)$ was increased between oscillation sequences.

All the results are presented in terms of the apparent frequency (Batzle et al., 2006) $f^{*}=f \times \eta_{f l} / 10^{-3}$, where $\eta_{f f}$ is the fluid viscosity in Pa.s. This is equivalent to normalizing the oscillation frequency by the viscosity of the fluid, taking water as the reference fluid with $\eta_{\text {wat }}=10^{-3} \mathrm{~Pa} \cdot \mathrm{s}$. Fluid's viscosity was chosen to be $\eta_{\text {air }}=10^{-5} \mathrm{~Pa} \cdot \mathrm{s}$ for the dry measurements, and $\eta_{g l y}=1 \mathrm{~Pa} \cdot \mathrm{s}$ for glycerin-saturated measurements. For all the samples' parameters presented in Table 1, the smallest $f_{b}$ was found to be around $2.4 \times 10^{8} \mathrm{~Hz}$ in water-saturated conditions for the coquina sample. Therefore, all the measurements fall within the quasi-static domain of poroelasticity, which also supports the use of the linear viscoelasticity formalism.

In the current experimental setup, the drained/undrained cutoff frequency for a global fluid diffusion along the sample's vertical length $(L)$ can be predicted by (Mavko et al., 2009)

$$
f_{1}^{*}=\frac{4 \kappa K_{d}}{\eta_{w a t} L^{2}}
$$

where $K_{d}$ is the drained bulk modulus. This formula is valid for a laterally sealed sample, with open/drained boundary conditions only at the top and bottom, thus creating a patchy length of $L / 2$ by symmetry. Predictions of $f_{1}^{*}$ are reported in Table 1 and on the following dispersion plots. We only report $f_{1}^{*}$ for $P_{\text {diff }}=2.5 \mathrm{MPa}$ as it barely varies with differential pressure.

The pressure dependence of the bulk modulus in dry conditions enables us to deduce a characteristic crack density $\rho$ and crack aspect ratio $\xi$ of the unconfined sample by Morlier's method (Morlier, 1971). The method was described in detail by Jaeger et al., (2009, pp. 291-294), and the effective medium is based on the noninteraction approximation between penny-shaped cracks. Once a characteristic aspect ratio $\xi$ is evaluated, which represents the dominant central aspect ratio of a distribution, a squirt flow cutoff frequency can be calculated by (Mavko et al., 2009)

$$
f_{2}^{*}=\frac{\xi^{3} K_{S}}{\eta_{w a t}}
$$




\section{COQUINA}
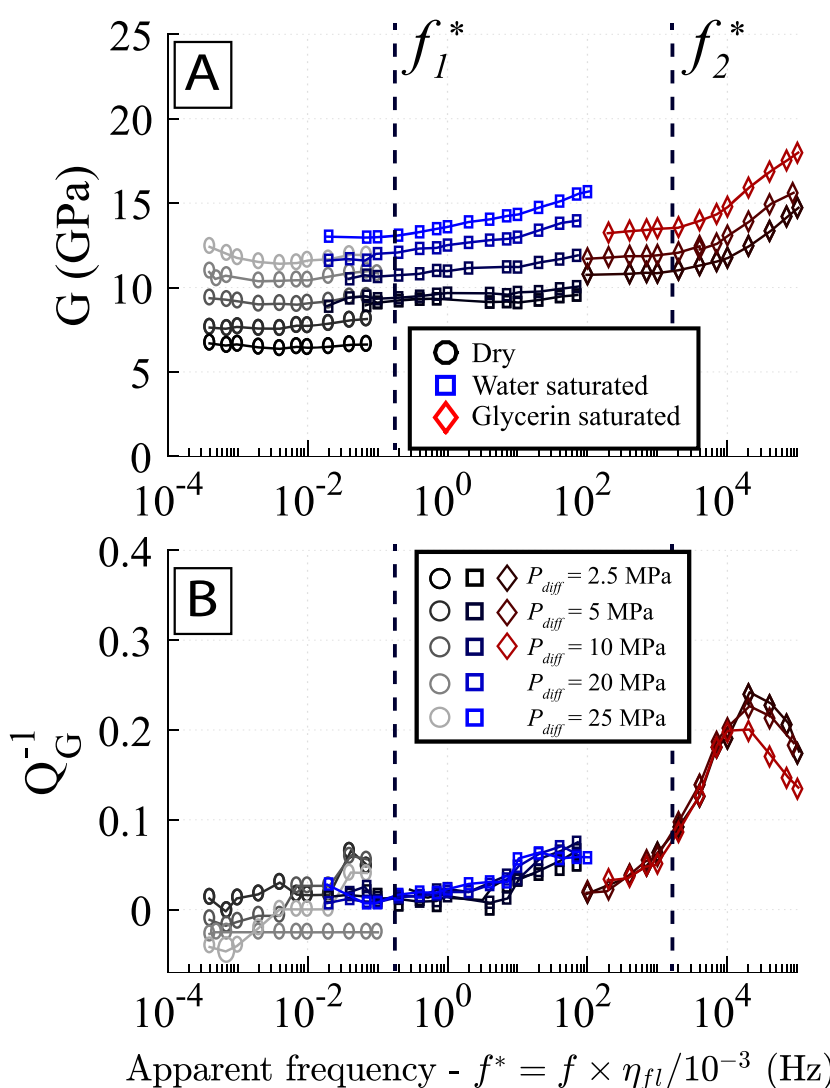

Figure 4. Results of the shear modulus dispersion (a) and attenuation (b) inferred from axial oscillations at different differential pressures on the coquina sample.

where $K_{S}$ is the skeleton bulk modulus, here taken equal to $77 \mathrm{GPa}$ for calcite. Similarly to $f_{1}^{*}$, the predictions for $f_{2}^{*}$ for each sample, in an unconfined state, are presented in Table 1 and are compared to the dispersion results for comparison. Note that $f_{2}^{*}<f_{b}$; this implies that squirt flow mechanism (not predicted by Biot theory) occurs before to reach the dynamic domain of poroelasticity.

\subsection{Coquina Sample}

For the coquina sample, the low-frequency axial and hydrostatic oscillations were performed at differential pressures between 2.5 and $25 \mathrm{MPa}$, in dry and water-saturated conditions and up to $10 \mathrm{MPa}$ for glycerin-saturated conditions.

4.1.1. E, $v$, and G Inferred From Axial-Stress Oscillations

In this section, we present the dispersion and attenuation (or related phase shift) results of the low-frequency axial oscillations, for $E, v$ and the inferred $G$ assuming isotropy. They are presented respectively in Figures 3 and 4 for dry and water- and glycerin-saturated conditions at different differential pressures. The relative uncertainties on $E, v$ and $G$ were found to be around $\Delta E / E=7 \%, \Delta v / v=4 \%$ and $\Delta G / G=7 \%$.

Young's modulus seems to exhibit only one major dispersive effect, visible in glycerin-saturated conditions above $10^{3} \mathrm{~Hz}$ (Figure 3a), which correlates with a peak in attenuation around $Q_{E}^{-1}=0.25$ (Figure $3 \mathrm{~b}$ ). No dispersion is visible in the dry measurements and a very small dispersion may be seen in water-saturated conditions around $0.2 \mathrm{~Hz}$, which seems to correlate with the predicted drained/undrained cutoff frequency $f_{1}^{*}$ (Figure 3a). The major dispersive phenomenon takes place around $10^{4} \mathrm{~Hz}$, visible in glycerin-saturated conditions, which seems to be within one order of magnitude of the cutoff frequency $f_{2}^{*}=1,600 \mathrm{~Hz}$ expected for squirt flow. This dispersion correlates well with attenuation peaks that seem to decrease only very slightly with increasing pressure (Figure 3b).

Poisson's ratio exhibits dispersion and peaks in the related phase shift $\tan \left(\varphi_{\text {rad }}-\varphi_{\text {ax }}\right)$ around $0.2 \mathrm{~Hz}$, which seems to correlate with the predicted drained/undrained cutoff frequency $f_{1}^{*}$ (Figures $3 \mathrm{c}$ and $3 \mathrm{~d}$ ). The peaks 


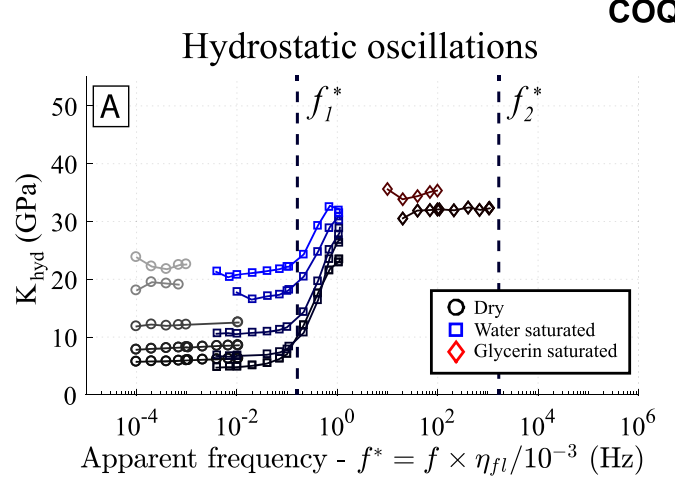

COQUINA
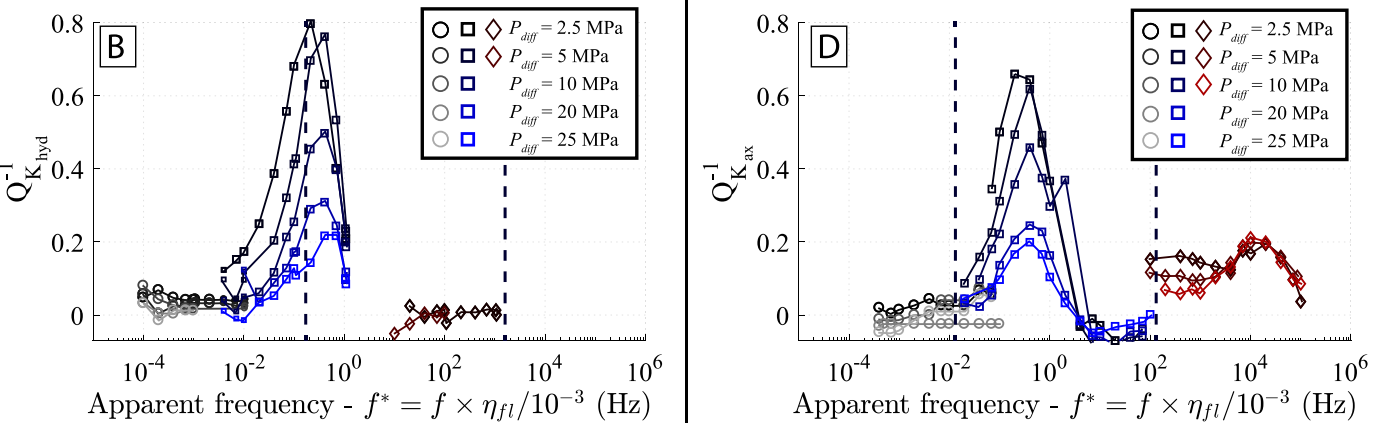

Figure 5. Results of the bulk modulus dispersion and attenuation measured from hydrostatic oscillations (a, b) and inferred from $E$ and $v$ from the axial oscillations (c, d) at different differential pressures on the coquina sample.

in the phase shifts decrease substantially with increasing differential pressure (Figure 3d). However, no dispersion is visible with glycerin around $10^{4} \mathrm{~Hz}$ as previously seen for $E$. On each side of what seems to be the drained/undrained cutoff frequency $\left(f_{1}^{*}\right)$, an increase of differential pressure seems to affect differently the Poisson's ratio. $v$ tends to increase in the drained regime, and tends to decrease in the undrained regime (Figure 3c).

The shear modulus results inferred from axial oscillations (linear combination of $E$ and $v$ ) are presented in Figure 4. We observe a very similar behavior as for the Young's modulus (Figure 3), except for what seemed to be the drained/undrained transition around $f_{1}^{*}$ that exhibits no dispersion/attenuation (Figure 4). This is consistent with Biot-Gassmann's theory where drained and undrained shear modulus are equivalent (Gassmann, 1951). Similarly to $E$, the major dispersion and attenuation occurs around $10^{4} \mathrm{~Hz}$ in glycerin-saturated conditions, with attenuation peaks evaluated around 0.25 (Figure $4 \mathrm{~b}$ ).

4.1.2. Bulk Modulus Inferred From Hydrostatic- and Axial-Stress Oscillations

The bulk modulus directly measured from the hydrostatic oscillations $\left(K_{\text {hyd }}\right)$, and inferred from $E$ and $v$ from the axial oscillations $\left(K_{a x}\right)$, are presented in Figure 5 . The relative uncertainties were found to be around $\Delta K_{\text {hyd }} / K_{\text {hyd }}=3 \%$ and $\Delta K_{a x} / K_{a x}=9 \%$. At first order, $K_{h y d}$ and $K_{a x}$ seem comparable over the frequency range. Both consistently exhibit strong dispersion around the drained/undrained cutoff frequency $f_{1}^{*}$ in water-saturated conditions (Figures $5 \mathrm{a}$ and $5 \mathrm{c}$ ), with associated attenuation peaks (Figures $5 \mathrm{~b}$ and $5 \mathrm{~d}$ ). We believe that the small differences between $K_{h y d}$ and $K_{a x}$, and their associated attenuation, are mainly due to uncertainties on the strain measurements, although we cannot rule out other potential sources of small discrepancies due to heterogeneity or anisotropy.

The dispersive transition that was observed for $E$ and $G$ around $10^{4} \mathrm{~Hz}$, seems to be visible on $K_{a x}$ under glycerin-saturated conditions (Figure $5 \mathrm{c}$ ). Indeed for $K_{h y d}$ the maximum frequency apparent frequency is $f^{*}=1.2 \times 10^{3} \mathrm{~Hz}$. However, the associated attenuation peak at $10^{4} \mathrm{~Hz}$ is much lower than the peak at $0.2 \mathrm{~Hz}$.

\subsection{Rustrel Sample}

\subsubsection{E, $v$, and G Inferred From Axial-Stress Oscillations}

The dispersion and attenuation (or related phase shift) of Young's modulus and Poisson's ratio resulting from the axial oscillations, in dry and water- and glycerin-saturated conditions are presented in Figure 6 . The differential pressures measured were $[2.5,5,10,20] \mathrm{MPa}$. The relative uncertainties on $E$ and $v$ were found 


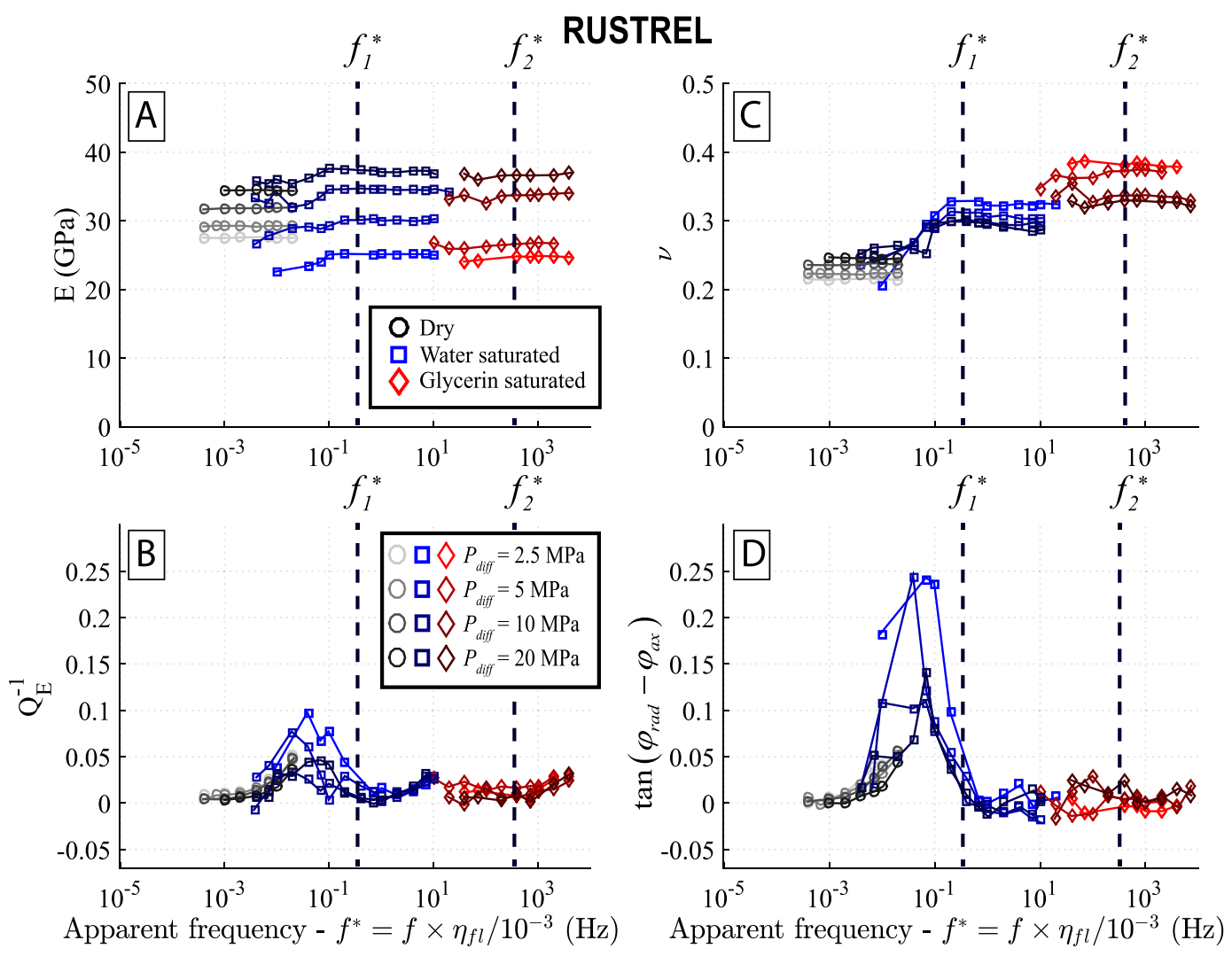

Figure 6. Results of the Young's modulus dispersion (a) and attenuation (b), and Poisson's ratio dispersion (c) and related phase shift $\tan \left(\varphi_{\text {rad }}-\varphi_{a x}\right)(\mathrm{d})$ obtained from axial oscillations at different differential pressures on the Rustrel sample.

to be around $\Delta E / E=3 \%$ and $\Delta v / \nu=4 \% . E$ exhibits small dispersion around $0.05 \mathrm{~Hz}$ (Figure 6a), correlated with attenuation (Figure $6 \mathrm{~b}$ ), visible under water-saturated conditions. $Q_{E}^{-1}$ has a maximum peak around 0.1 for $P_{\text {diff }}=2.5 \mathrm{MPa}$ and decreases with increasing differential pressure. This dispersion seems to correspond to the drained/undrained transition, although the predicted value of $f_{1}^{*}=0.36 \mathrm{~Hz}$ overestimates slightly the experimental value. No dispersion, nor attenuation, is detected for higher apparent frequencies in the range 1 to $10^{4} \mathrm{~Hz}$ (Figures 6a and 6b).

The Poisson's ratio exhibits a similar dispersive transition around $0.05 \mathrm{~Hz}$ (Figure $6 \mathrm{c}$ ) in water-saturated conditions, that seems related to the drained/undrained transition. The corresponding phase $\operatorname{shift} \tan \left(\varphi_{\text {rad }}-\varphi_{\text {ax }}\right)$ shows a clear peak, which is much higher than for $Q_{E}^{-1}$ (Figure 6d). Similarly to the coquina sample, in the drained regime (below $f_{1}^{*}$ ) $v$ increases with differential pressure, whereas it decreases in the undrained regime (Figure 6c). Similarly to $E$, the Poisson's ratio does not exhibit any dispersion at higher frequencies up to $10^{4} \mathrm{~Hz}$ (Figure 6c).

The dispersion and attenuation of the Rustrel's shear modulus, deduced from $E$ and $v$, are presented in Figures $7 \mathrm{a}$ and $7 \mathrm{~b}$. The relative uncertainty on $G$ was found to be around $\Delta G / G=3 \%$. No dispersion nor attenuation were observed along the whole frequency range.

\subsubsection{Bulk Modulus Inferred From Hydrostatic-Stress Oscillations}

The bulk modulus dispersion and attenuation, directly measured from hydrostatic oscillations $\left(K_{\text {hyd }}\right)$, are presented in Figures $7 \mathrm{c}$ and $7 \mathrm{~d}$. The maximum relative uncertainty was found to be around $\Delta K_{\text {hyd }} / K_{\text {hyd }}=$ $2 \%$. A strong dispersion, correlated with high attenuation peaks, is visible between 0.05 and $0.1 \mathrm{~Hz}$, which correlates with the predicted drained/undrained cutoff frequency $f_{1}^{*}$. As for E and $v$, no dispersive transition is detected for frequencies higher than $f_{1}^{*}$ up to $10^{4} \mathrm{~Hz}$, even within the vicinity of the potential squirt flow cutoff frequency $f_{2}^{*}$ (Figure $7 \mathrm{c}$ ). 


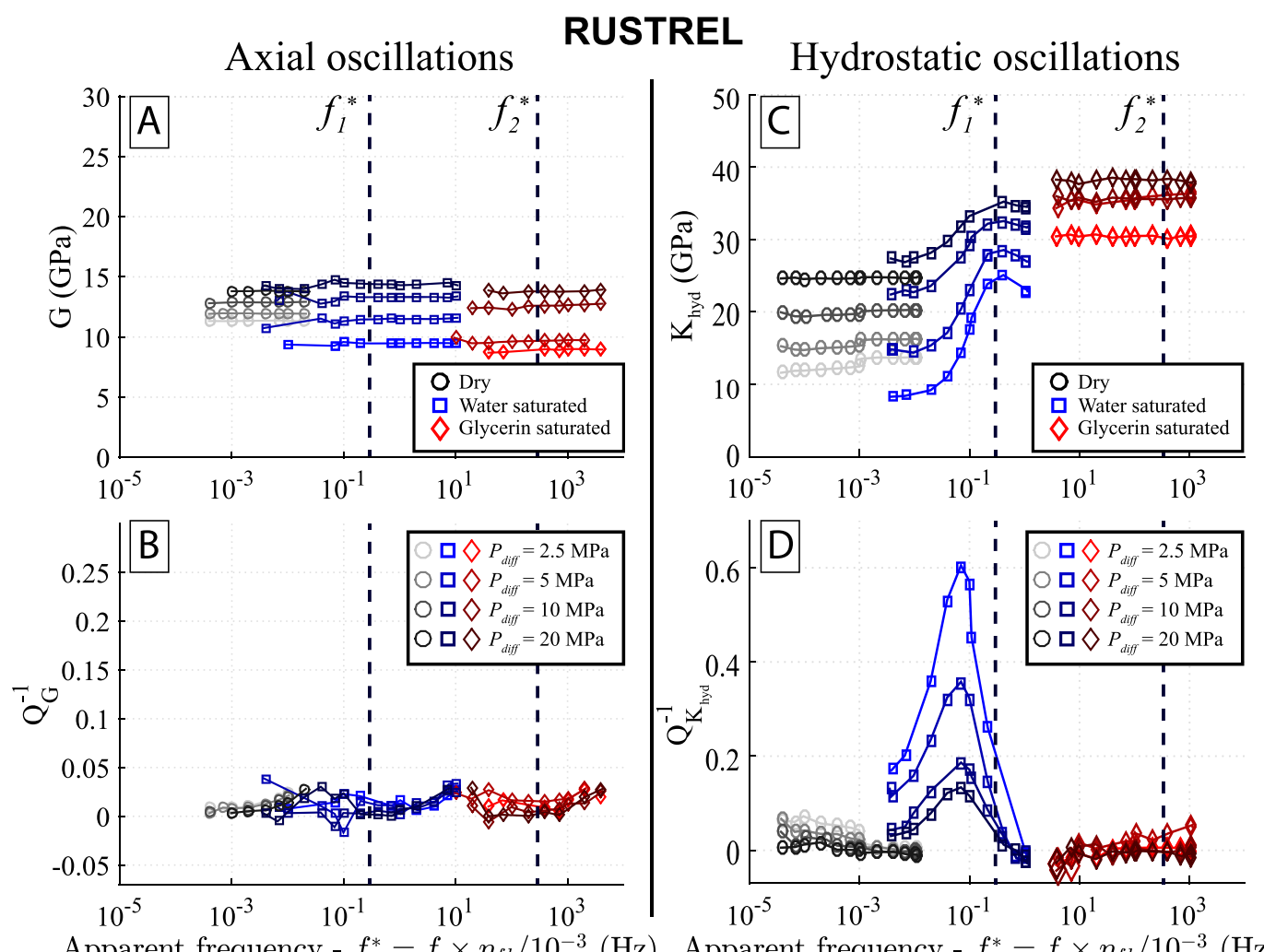

Apparent frequency - $f^{*}=f \times \eta_{f l} / 10^{-3}(\mathrm{~Hz})$ Apparent frequency - $f^{*}=f \times \eta_{f l} / 10^{-3}$

Figure 7. Results of dispersion and attenuation of the shear modulus ( $a, b)$ obtained from axial oscillations, and of the bulk modulus (c, d) obtained from hydrostatic oscillations at different differential pressures on the Rustrel sample.

\subsection{Indiana Samples}

\subsubsection{Bulk Modulus Inferred From Hydrostatic-Stress Oscillations}

Hydrostatic oscillations only were performed on the Indiana samples within the frequency range of $[0.01 ; 1] \mathrm{Hz}$, at the differential pressures of $[2.5 ; 5 ; 10 ; 20] \mathrm{MPa}$. The full set of results are presented in Figure 8 . The relative uncertainty due to the strain gauges was around $\Delta K / K=2 \%$ for the intact sample, and $\Delta K / K=5 \%$ for the thermally cracked one. $K_{h y d}$ of the intact sample exhibits one dispersive transition between $10^{-2}$ and $1 \mathrm{~Hz}$ under water-saturated conditions (Figures $8 \mathrm{a}$ and $8 \mathrm{~b}$ ). As the bulk modulus increases from 21 to $34 \mathrm{GPa}$ with increasing differential pressure, the amount of dispersion decreases. The attenuation peaks decrease from 0.19 to 0.06 with increasing differential pressure, and are all centered around $0.1 \mathrm{~Hz}$ (Figure $8 \mathrm{~b}$ ). This dispersive transition correlates well with the drained/undrained cutoff frequency $f_{1}^{*}=0.25 \mathrm{~Hz}$ of the intact sample.

The bulk modulus of the thermally cracked sample exhibits two noticeable dispersive transitions, between $10^{-2}$ and $1 \mathrm{~Hz}$ under water-saturated conditions and between 10 and $10^{3} \mathrm{~Hz}$ under glycerin-saturated conditions (Figure 8c). Both transitions are consistent with two attenuation peaks around $8 \times 10^{-2}$ and $10^{2} \mathrm{~Hz}$ (Figure 8d). With the increase of the differential pressure, the dry bulk modulus increases from 6 to $20 \mathrm{GPa}$, and the amount of dispersion decreases for both transitions. With increasing differential pressure from 2.5 to $20 \mathrm{MPa}$, the first attenuation peak decreases from 0.3 to 0.1 , and the second peak decreases from 0.25 toward 0 just above $P_{\text {diff }}=10 \mathrm{MPa}$ (Figure $8 \mathrm{~d}$ ), although it seems that the peaks shift to lower frequencies with increasing pressure. The first transition correlates well with the predicted drained/undrained cutoff frequency $f_{1}^{*}=0.1 \mathrm{~Hz}$, and the second transition seems to correlate well with the predicted undrained/unrelaxed cutoff frequency $f_{2}^{*}=230 \mathrm{~Hz}$ related to potential squirt flow.

\section{Discussion}

\subsection{Identifying the Fluid-Flow Regimes}

Low-frequency forced oscillations methods in both axial and hydrostatic modes proved to be an effective way to monitor the evolution of all the dynamic moduli with frequency and to monitor how each modulus is 


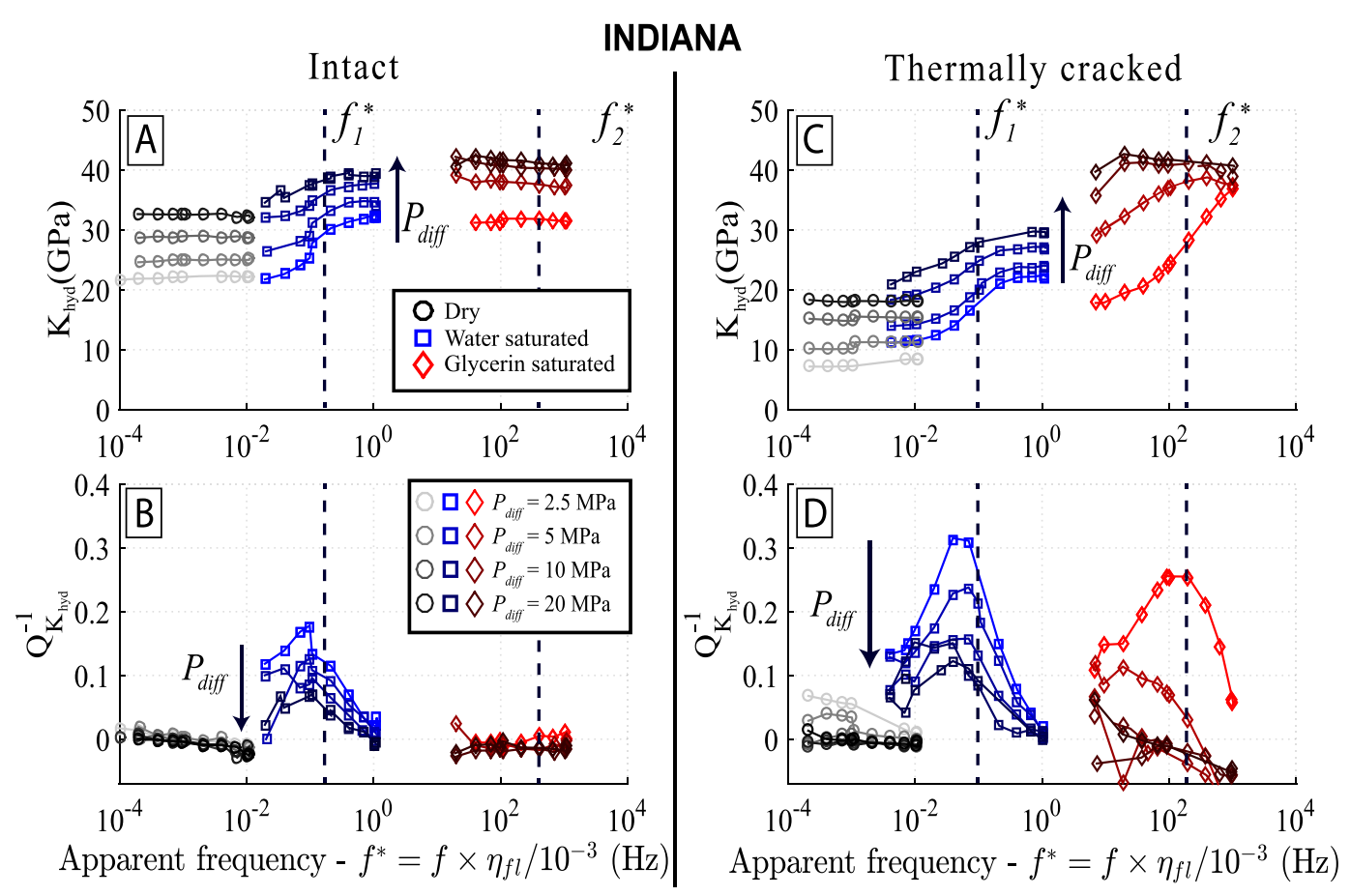

Figure 8. Results of the bulk modulus dispersion and attenuation obtained from the hydrostatic oscillations on the Indiana limestone before $(\mathrm{a}, \mathrm{b})$ and after thermal cracking at $500^{\circ} \mathrm{C}(\mathrm{c}, \mathrm{d})$.

affected by the different dispersion mechanisms. We point out that the measured dispersion and attenuation were deduced from local strain measurements at the center of the sample (averaged around the periphery). Although the squirt flow mechanism should be equivalent in all the REVs regardless of the position, the frequency range of the measured (local) drained/undrained transition may be strongly affected by the position of the strain gauges with respect to the experimental drained boundaries (Pimienta, Borgomano, et al., 2016).

Broadband measurements on a small sample with drained boundary conditions may exhibit different fluid-flow regimes at global or local scales, once excluded possible patchy saturation, inertial (Biot dynamic regime) or scattering effects. At the sample's scale, although mesoscopic flows between different parts of the sample cannot be completely excluded, the compressibility contrasts are unlikely to generate as much attenuation as squirt flow between compliant cracks and round pores. Clearly identifying the frequency ranges of the fluid-flow regimes would allow to access the drained, the undrained and the potential unrelaxed moduli for a given differential pressure. In addition to the predicted cutoff frequencies $f_{1}^{*}$ and $f_{2}^{*}$ given by equations (5) and (6), the use of Biot-Gassmann's equation, that predicts the undrained bulk modulus $\left(K_{u}\right)$ from the dry bulk modulus $\left(K_{d r y}\right)$, and the use of a squirt flow model from Gurevich et al. (2010) can support the identification of the fluid-flow regimes along the frequency range.

Biot-Gassmann predicts that the drained and undrained shear moduli are equal. After verifying the consistency between the dry and drained measurements to exclude fluid/solid chemical interactions, the Biot-Gassmann's poroelastic prediction of $K_{u}$ can be calculated by

$$
K_{u}=K_{d r y}+\frac{K_{f}\left(1-\frac{K_{d r y}}{K_{S}}\right)^{2}}{\phi+\left(\left(1-\frac{K_{d r y}}{K_{S}}\right)-\phi\right) \frac{K_{f}}{K_{S}}},
$$

where, $K_{S}$ is the skeleton modulus, $K_{f}$ is the fluid's bulk modulus, and $\phi$ the porosity. For all our samples, we used $K_{S}=77 \mathrm{GPa}$, taken as the calcite bulk modulus (Mavko et al., 2009). Biot-Gassmann's prediction was calculated for the lowest and highest differential pressures and compared to the sample's dispersion results in Figures 9 and 10. The bulk moduli of water and glycerin $\left(K_{f}\right)$ were taken equal to 2.24 and $4.36 \mathrm{GPa}$ 


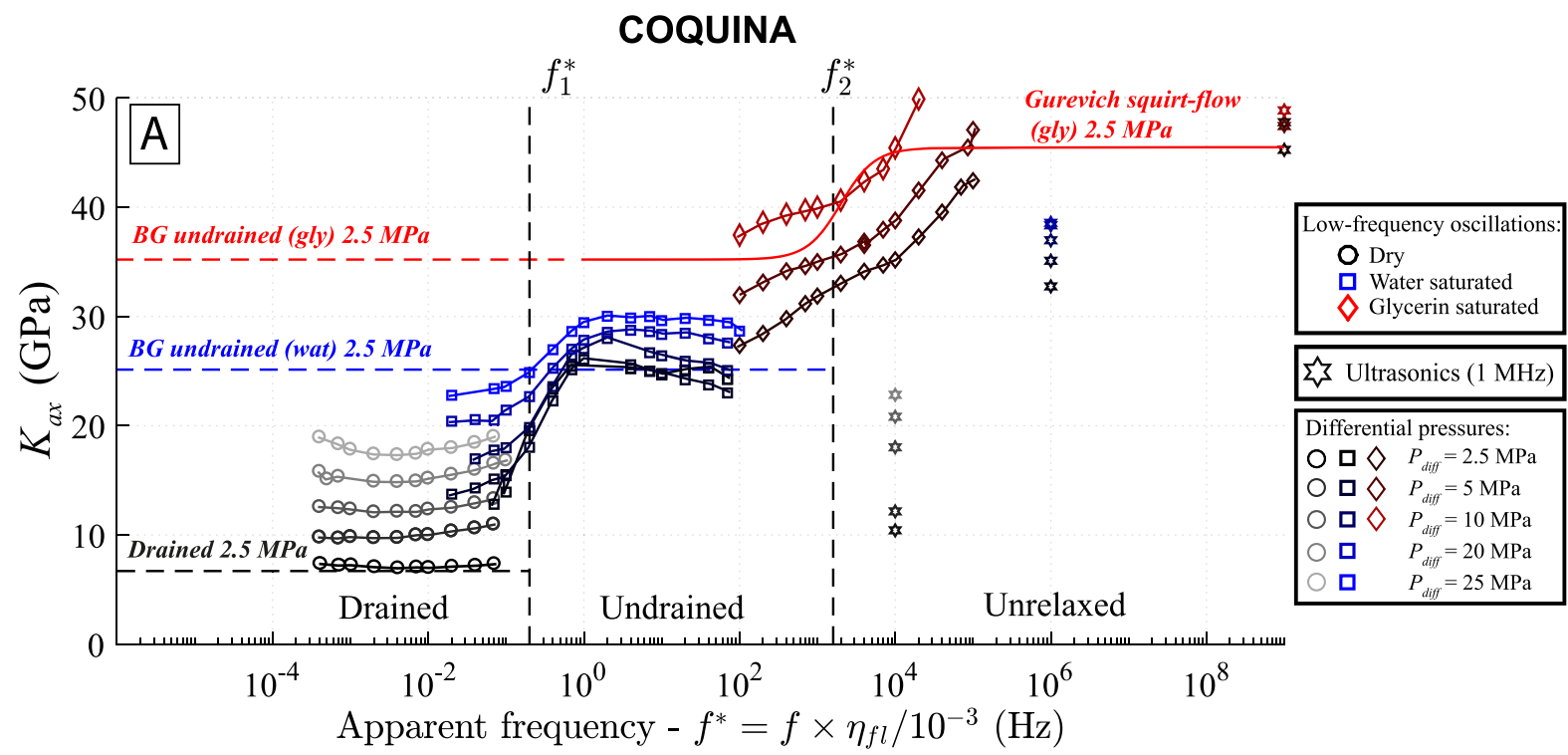

RUSTREL

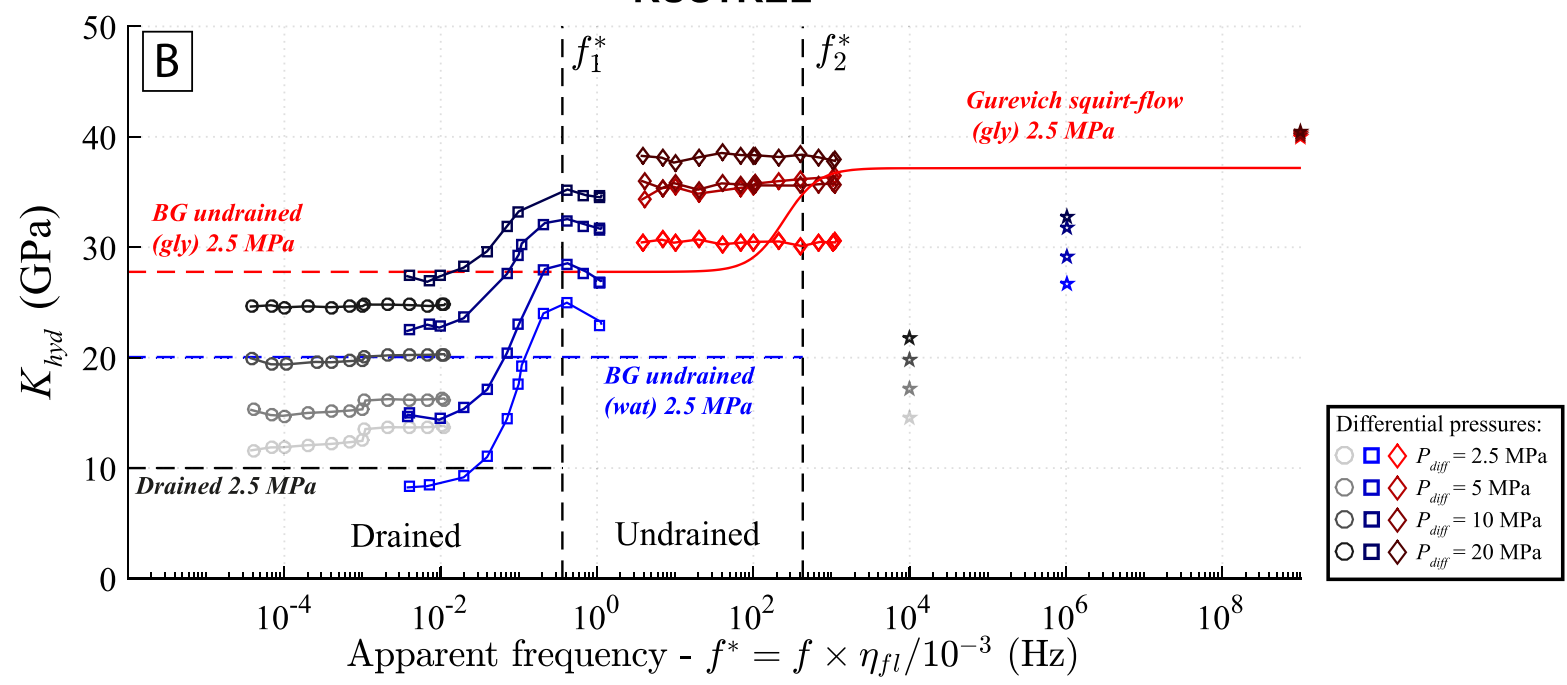

Figure 9. Interpretation of the frequency dependence of the bulk modulus for the coquina (a) and the rustrel (b) samples, in terms of drained, undrained, or unrelaxed (squirt flow) fluid-flow regimes. Biot-Gassmann (BG) prediction of the undrained moduli for $P_{\text {diff }}=2.5 \mathrm{MPa}$ are compared to the results (horizontal dashed lines), along with the squirt flow model from Gurevich et al. (2010) (solid line) under glycerin-saturated conditions, using the parameters of Table 1. $f_{1}^{*}$ and $f_{2}^{*}$ are the predicted cutoff frequencies for the drained/undrained transition and the potential squirt flow, respectively.

respectively, and the porosities are given in Table 1. Moreover, the low-frequency bulk moduli results are compared to the moduli inferred from ultrasonic measurements $(1 \mathrm{MHz})$ in Figures 9 and 10. In addition, we can use the crack parameters $\left(\xi, \phi_{c}\right)$ deduced from Morlier's method (Morlier, 1971), and high-pressure "dry" bulk modulus $\left(K_{h}\right)$ defined in Table 1 to compute the squirt flow model for $K$ (equations 9, 18, 19, and 22 of Gurevich et al., 2010), assuming randomly oriented penny-shaped cracks. The model was tested for all the samples in glycerin-saturated conditions at $P_{\text {eff }}=2.5 \mathrm{MPa}$.

\subsubsection{Coquina}

We recall that the bulk modulus was obtained by two methods, and we found that $K_{\text {hyd }} \simeq K_{a x}$ as expected for an isotropic medium (Figure 5). For $P_{\text {diff }}=2.5 \mathrm{MPa}$ and $P_{\text {diff }}=25 \mathrm{MPa}, K_{d r y}$ was taken equal to 7 and $19 \mathrm{GPa}$, respectively. This yields predicted undrained moduli $K_{u}$ (equation (7)) of respectively 25.6 and 32.4 GPa under water-saturated conditions, and respectively 36.4 and $40.7 \mathrm{GPa}$ under glycerin-saturated conditions (Figure 9a). We observe that above $f_{1}^{*}=0.16 \mathrm{~Hz}$ in water-saturated conditions, the measured $K_{a x}$ tend toward Biot-Gassmann's predictions (Figure 9a), consistently for the drained/undrained transition. At 

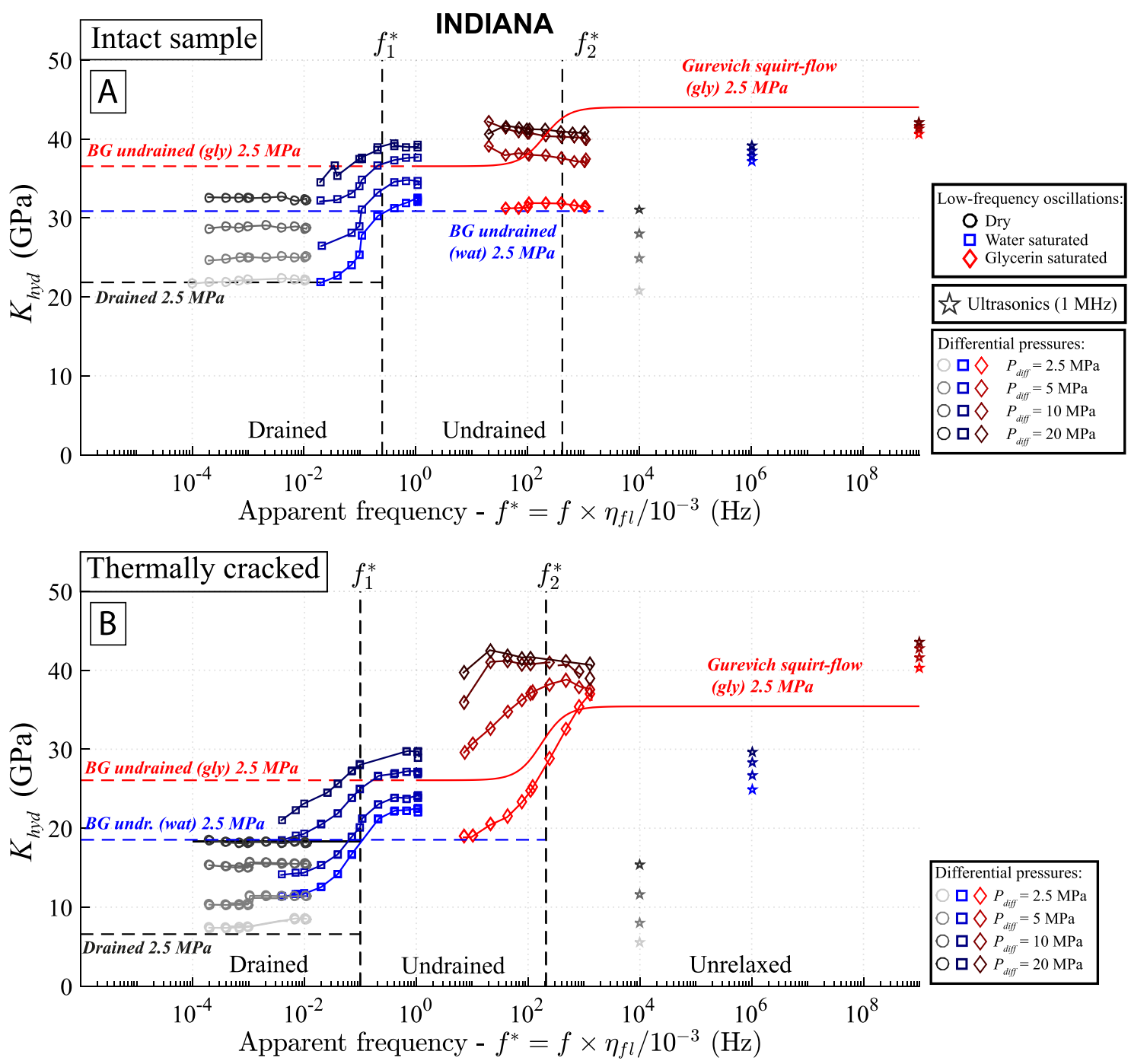

Figure 10. Interpretation of the frequency dependence of the bulk modulus for the intact Indiana (a) and the thermally cracked Indiana (b) samples, in terms of drained, undrained, or unrelaxed (squirt flow) fluid-flow regimes. Biot-Gassmann (BG) predictions of the undrained moduli for $P_{\text {diff }}=2.5 \mathrm{MPa}$ are compared to the results (horizontal dashed lines), along with the squirt flow model from Gurevich et al. (2010) (solid line) under glycerin-saturated conditions, using the parameters of Table 1. $f_{1}^{*}$ and $f_{2}^{*}$ are the predicted cutoff frequencies for the drained/undrained transition and the potential squirt flow, respectively.

frequencies lower than $f_{2}^{*}=1,600 \mathrm{~Hz}$ in glycerin-saturated conditions, Biot-Gassmann seems to slightly over-predict the measured $K_{a x}$.

When the frequency increases above $f_{2}^{*}$, the measured $K_{a x}$ increase at values greater than Biot-Gassmann and tend toward the ultrasonic measurements with glycerin (Figure 9a). Such behavior seems consistent with an undrained/unrelaxed transition generated by local flow within the REV, as shows the good comparison with the squirt flow model. The ultrasonic measurements in dry conditions are consistent with the low-frequency measurements, which suggests the absence of scattering. The water-saturated ultrasonic results $\left(10^{6} \mathrm{~Hz}\right)$ are consistently greater than the undrained moduli. The proximity of the second dispersion, visible in glycerin-saturated conditions, with the predicted frequency for squirt flow $\left(f_{2}^{*}\right)$ and the squirt flow model supports the idea that local flow dispersion was indeed observed. The dispersion of the experimental results, however, seems to occur a slightly higher frequencies as the model and $f_{2}^{*}$ predict. This may be explained by a slightly wrong estimation on $\xi$, which can induce large errors on the squirt flow cutoff frequency (equation (6)).

We recall that the sample did not bear much intergranular calcitic cement, which makes it a rather unconsolidated rock and very compliant at low differential pressures as suggested by the bulk moduli measurements 
(Figure 5). The porosity seems mainly of intergranular porosity in triple junctions and between grain contacts, which may be responsible for the squirt flow. Interestingly, such a detritic microstructure seems close to that of sandstones, along with the frequency dependence of the dynamic moduli (e.g., Chapman et al., 2019; Pimienta et al., 2015a, 2017; Subramaniyan et al., 2015; Yin et al., 2017).

\subsubsection{Rustrel}

For $P_{\text {diff }}=2.5 \mathrm{MPa}$ and $P_{\text {diff }}=20 \mathrm{MPa}, K_{d r y}$ was taken equal to 10 and $25 \mathrm{GPa}$, respectively. This yields predicted undrained moduli $K_{u}$ (equation (7)) of respectively 20.0 and $31.2 \mathrm{GPa}$ under water-saturated conditions, and respectively 27.4 and $36.1 \mathrm{GPa}$ under glycerin-saturated conditions (Figure 9b). We observe that, in the transition near $f_{1}^{*}=0.36 \mathrm{~Hz}$ in water-saturated conditions, the measured $K_{\text {hyd }}$ increases toward Biot-Gassmann's predictions (Figure 9b), consistently for the drained/undrained transition. At frequencies lower than $f_{2}^{*}=477 \mathrm{~Hz}$, the results of $K_{\text {hyd }}$ in glycerin-saturated conditions are also consistent with Biot-Gassmann (Figure 9b), supporting the interpretation of an undrained regime between $f_{1}^{*}$ and $f_{2}^{*}$.

The dry ultrasonic results are consistent with the low-frequency moduli (Figure 9b) which suggests absence of scattering effects. In fluid-saturated conditions, the ultrasonic results seem to be slightly greater than the undrained moduli. In glycerin-saturated conditions there is a good consistency between the high-frequency end of the squirt flow model and the ultrasonic results. However, no dispersion could be observed in the experiments around $f_{2}^{*}$ as predicted by the model (Figure 9b). We speculate that a very limited dispersion may occur at frequencies higher than predicted, which again may be explained by a slightly wrong estimation of $\xi$.

\subsubsection{Indiana}

For the intact sample at $P_{\text {diff }}=2.5 \mathrm{MPa}$ and $P_{\text {diff }}=20 \mathrm{MPa}, K_{d r y}$ was taken equal to 22 and $32.5 \mathrm{GPa}$, respectively. This yields predicted undrained moduli $K_{u}$ (equation (7)) of respectively 30.7 and $38.4 \mathrm{GPa}$ under water-saturated conditions, and respectively 36.5 and $42.9 \mathrm{GPa}$ under glycerin-saturated conditions (Figure 10a). We observe that the dispersion in water-saturated results seem consistent with both Biot-Gassmann and $f_{1}^{*}=0.25 \mathrm{~Hz}$ predictions, consistently for the drained/undrained transition. The glycerin-saturated results, at frequencies below $f_{2}^{*}=420 \mathrm{~Hz}$, seem to be consistent with Biot-Gassmann's predictions and, therefore, the undrained regime (Figure 10a). The ultrasonic measurements in fluid-saturated conditions seem to agree with Biot-Gassmann's high pressure prediction for the undrained moduli. Similarly to the Rustrel sample, no dispersion was visible within the vicinity of $f_{2}^{*}$, as did the squirt-model predict. By comparing the ultrasonic results and the undrained moduli, only a small dispersion may possibly occur between $10^{4}$ and $10^{6} \mathrm{~Hz}$, at very low differential pressures.

For the thermally cracked Indiana sample at $P_{\text {diff }}=2.5 \mathrm{MPa}$ and $P_{\text {diff }}=20 \mathrm{MPa}, K_{d r y}$ was taken equal to 6.5 and $18 \mathrm{GPa}$, respectively. This yields predicted undrained moduli $K_{u}$ (equation (7)) of respectively 18.2 and 26.4 GPa under water-saturated conditions, and respectively 26.5 and $32.7 \mathrm{GPa}$ under glycerin-saturated conditions (Figure 10b). We observe that the dispersion in water-saturated results seem consistent with both Biot-Gassmann and $f_{1}^{*}=0.1 \mathrm{~Hz}$ predictions, consistently for the drained/undrained transition. The glycerin-saturated results exhibit strong dispersion within the vicinity of $f_{2}^{*}=230 \mathrm{~Hz}$, especially for the low differential pressures (Figure 10b). With increasing frequency, the glycerin-saturated moduli increase toward the ultrasonic results, which are all much greater than Biot-Gassmann's undrained predictions.

The squirt flow model seems to predict the frequency range of the dispersion but not its amplitude (Figure 10b). We speculate that this may be related to the high pressure bulk modulus $K_{h}$ used to model the squirt flow, which may have been underestimated due to the lack of data above $20 \mathrm{MPa}$. Interestingly, if we use the same $K_{h}$ of the intact sample (34 GPa instead of $23 \mathrm{GPa}$ ), which we would expect if we solely added cracks to the medium, the squirt flow model would be consistent with the results, with a high-frequency value around $42.3 \mathrm{GPa}$, instead of 35.6 GPa as represented in Figure 10b. However, we fail to explain why Biot-Gassmann overestimates the results in glycerin-saturated conditions under $100 \mathrm{~Hz}$ at $P_{\text {diff }}=2.5 \mathrm{MPa}$.

The water-saturated ultrasonic results are consistently greater than the undrained moduli, while the dry measurements exhibit no dispersion (Figure 10b). Therefore, a clear distinction can be made between the drained, undrained and unrelaxed regimes. The consistency of the second dispersion, visible in glycerin-saturated conditions, with the predicted frequency $f_{2}^{*}$ and the model supports the idea of a squirt flow mechanism generated by the thermally induced cracks. 

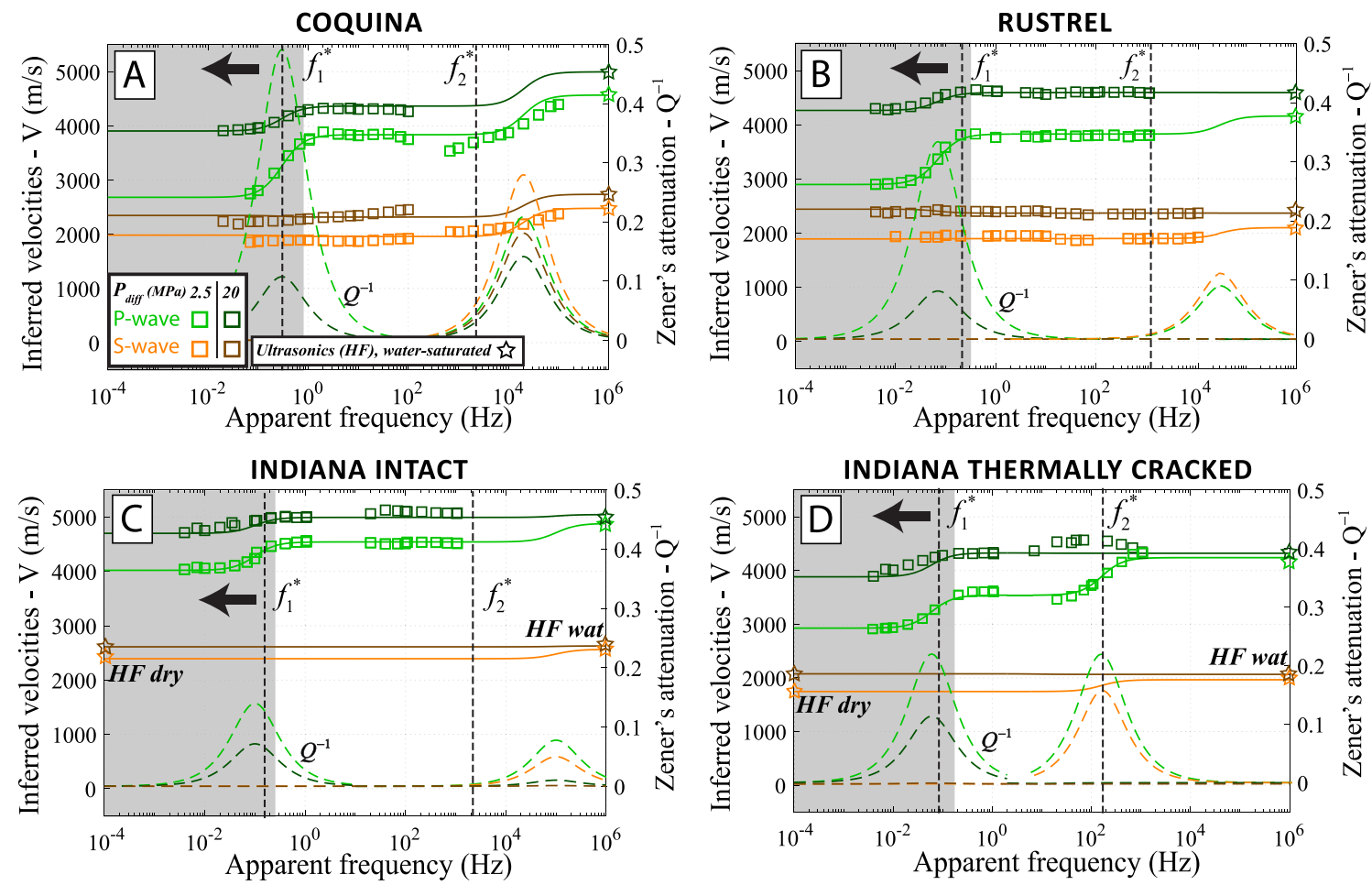

Figure 11. Inferred $P$ and $S$ wave velocity dispersion/attenuation for water-saturated conditions of the coquina (a), Rustrel (b), intact (c), and thermally cracked (d) Indiana samples. "HF dry" and "HF wat" designate the high-frequency results obtained from ultrasonic measurements, respectively under dry and water-saturated conditions. Zener model is used to calculate the attenuation from the dispersion. The gray zone represents the drained fluid-flow regime conditioned by the length of the sample and its permeability, which would be pushed to much lower frequencies in the field. For the Indiana samples (c and d), the ultrasonic $S$-wave velocity in dry conditions (HF dry), corrected with water-saturated density, is assumed equal to the drained and undrained $S$ wave velocity that would be observed at lower frequencies.

\subsection{Inferred $P$ and $S$ Wave Dispersion and Attenuation}

To synthesize all the previous observations, we present in Figure 11 the inferred $P$ and $S$ wave dispersion and attenuation for all the samples at the lowest and highest differential pressures, associated with photomicrographs under reflected light of there microstructures saturated with blue colorant. The velocities are calculated for fully saturated conditions with water. For an isotropic elastic medium, the velocity dispersion of the $P$ and $S$-waves are given by

$$
V_{P}(\omega)=\sqrt{\frac{K(\omega)+\frac{4}{3} G(\omega)}{D}} \text { and } \quad V_{S}(\omega)=\sqrt{\frac{G(\omega)}{D}},
$$

where $D$ is the density of the medium.

For consistency with the field and to take into account the difference between the bulk moduli of water and glycerin $\left(K_{w a t}=2.24 \mathrm{GPa}\right.$ and $\left.K_{g l y}=4.36 \mathrm{GPa}\right)$, we substituted glycerin to water using Biot-Gassmann equation for the bulk modulus (Spencer $\&$ Shine, 2016). The medium density was taken as $D=D_{d r y}+\phi D_{\text {wat }}$. Zener's viscoelastic model is used to evaluate the attenuation related to the $P$ wave and $S$ wave dispersion. Zener's model is a simple method to evaluate the dissipated elastic energy knowing the initial $\left(M_{0}\right)$ and final $\left(M_{1}\right)$ moduli of the dispersion, assuming only one viscous mechanism is acting (Borgomano et al., 2017). The exact attenuation may be calculated from the dispersion using Kramers-Kronig relationships (Mikhaltsevitch et al., 2016b). However, the method implies the need of a good frequency resolution in data points in order to calculate the local derivatives of the dispersion. In Zener's spring-damper representation, $M_{a}=M_{1}$ and $M_{b}^{-1}=\left(M_{0}^{-1}-M_{1}^{-1}\right)$ represent the spring's moduli, $\eta_{b}=M_{1} /\left(2 \pi f_{c}\right)$ represents the dashpot parallel to $M_{b}$ where $f_{c}$ is the adjustable cutoff frequency. With the approximation $M_{a} \ll M_{b}$, the attenuation $Q_{M}^{-1}$ of the wave modulus $M$ is given by

$$
Q_{M}{ }^{-1} \approx \frac{2 \pi f \tau}{1+(2 \pi f)^{2} \tau^{2}}\left(\frac{M_{1}}{M_{0}}-1\right),
$$


where $\tau^{-1}=2 \pi f_{c}\left(\frac{M_{1}}{M_{0}}-1\right)$.

The drained/undrained cutoff frequency depends on permeability and sample's size (equation (5)). In the field, the characteristic diffusion length to achieve drained conditions would correspond to half a wavelength, which is much larger than the sample's length in our experiments. Thus for field measurements, the drained regime, represented by the gray-colored areas in Figure 11, would therefore be pushed to much lower frequencies as represented here. However, the frequencies above $f_{1}^{*}$ are unaffected by the sample's size and represent the intrinsic properties of the saturated REV, in the absence of any other heterogeneities at larger scale. Although we still calculated an attenuation peak for the drained/undrained transitions for the sake of illustration, we shall focus more on the higher frequency mechanisms susceptible to affect seismic $(100 \mathrm{~Hz})$, sonic $(10 \mathrm{kHz})$, and ultrasonic $(1 \mathrm{MHz})$ measurements.

\subsubsection{Coquina}

For the coquina sample, $K_{a x}$ and $G_{a x}$ were used to calculate the velocities, along with the ultrasonic measurements. The $P$ wave velocity at $P_{\text {diff }}=2.5 \mathrm{MPa}$ was found to be less than $2800 \mathrm{~m} / \mathrm{s}$ in the drained regime, and around $4000 \mathrm{~m} / \mathrm{s}$ at $P_{\text {diff }}=20 \mathrm{MPa}$ (Figure 11a). The drained/undrained transition would generate high $P$ wave attenuation peaks at 0.5 and 0.1 for $P_{\text {diff }}=2.5 \mathrm{MPa}$ and $P_{\text {diff }}=20 \mathrm{MPa}$, respectively. A substantial amount of dispersion related to squirt flow was observed around $2 \times 10^{4} \mathrm{~Hz}$ (Figure 11a), affecting both the $P$ wave and the $S$ wave velocities. At $P_{\text {diff }}=2.5 \mathrm{MPa}, V_{P}$ increases by more than $600 \mathrm{~m} / \mathrm{s}$ and $V_{S}$ increases by $400 \mathrm{~m} / \mathrm{s}$ (Figure 11a). The attenuation peaks for the $S$ wave are higher than for the $P$ wave, respectively around 0.28 and 0.2 at $P_{\text {diff }}=2.5 \mathrm{MPa}$. We recall that for $f>f_{1}$ the results can be directly applied for field measurements. For this rock, squirt flow is nonnegligible and occurs in the frequency range of sonic log measurement. Similar observations were made for sandstones (e.g., Chapman et al., 2019; Pimienta et al., 2015a, 2017; Yin et al., 2017).

\subsubsection{Rustrel}

For the Rustrel sample, $K_{\text {hyd }}$ and $G_{a x}$ were used to calculate the velocities, along with the ultrasonic measurements. The experimental results do not show much dispersion at frequencies higher than $f_{1}^{*}$, despite a noticeable effect of the differential pressure on $V_{P}$ and $V_{S}$ (Figure 11b), which would have suggested crack closure and potential crack-to-pore squirt flow. After the drained/undrained transition, the amount of dispersion of $V_{P}$ is of maximum $200 \mathrm{~m} / \mathrm{s}$ for $P_{\text {diff }}=2.5 \mathrm{MPa}$, for an attenuation peak of 0.09 , and is nil for $P_{\text {diff }}=20 \mathrm{MPa}$. The $S$ wave shows a dispersion less than $100 \mathrm{~m} / \mathrm{s}$ for an attenuation peak of 0.11 . This low amount of dispersion may occur between $10^{4}$ and $10^{6} \mathrm{~Hz}$, only slightly affecting sonic log frequencies.

\subsubsection{Indiana}

For the Indiana samples, the $P$ wave velocities were inferred from $K_{\text {hyd }}$ and ultrasonic $S$ wave results (Figures 11c and 11d). Since we could not infer shear moduli from axial-stress oscillations, we used the dry and water-saturated ultrasonic measurements for the drained (= undrained) and the unrelaxed regimes, respectively.

For the intact sample, the velocities showed little dependence to effective pressure, consistent with the absence of cracks and with a strongly cemented intergranular space. Beyond the undrained regime $\left(f_{1}^{*}\right)$, only little dispersion may affect the velocities at low pressure (Figure 11c). At $P_{\text {diff }}=2.5 \mathrm{MPa}$, there may be some dispersion around $10^{5} \mathrm{~Hz}$, but none at $P_{\text {diff }}=20 \mathrm{MPa}$. The maximum change in $P$ wave velocity would be of $300 \mathrm{~m} / \mathrm{s}$ in water-saturated conditions is possible with an attenuation peak of 0.08 . The dispersion on the $S$ wave would be of maximum $100 \mathrm{~m} / \mathrm{s}$, with an attenuation peak of 0.05 (Figure 11c). Again, this low amount of dispersion may occur around $10^{5} \mathrm{~Hz}$, only slightly affecting the sonic log frequencies, similarly to the Rustrel sample.

After the previous Indiana sample was thermally cracked, beyond the undrained regime $\left(f_{1}^{*}\right)$, a strong dispersion can be observed around the predicted cutoff frequency of squirt flow $f_{2}^{*}=230 \mathrm{~Hz}$, affecting both the $P$ wave and the $S$ wave at low pressures (Figure 11d). At $P_{\text {diff }}=20 \mathrm{MPa}$ no more dispersion seem to occur. The $P$ wave velocity may increase nearly $800 \mathrm{~m} / \mathrm{s}$, with an attenuation peak of 0.22 , at $P_{\text {diff }}=2.5 \mathrm{MPa}$. The inferred $S$ wave dispersion may show a dispersion of about $300 \mathrm{~m} / \mathrm{s}$ with an attenuation peak of 0.16 (Figure 11d). The newly induced cracks substantially increased the pressure-dependence of the velocities, which are now lower than for the intact sample. The consistency of the measured dispersion with the predicted cutoff frequency $f_{2}^{*}$, supports the idea that squirt flow is at play in the newly formed cracks. Moreover, the intact sample did not bear any dispersion in the same frequency range. Interestingly, this squirt flow dispersion is in the vicinity of the seismic frequencies for water-saturated conditions (Figure 11d), whereas it was occurring at sonic frequencies for the coquina limestone (Figure 11a). 


\subsection{Effect of Thermal Cracking}

After we thermally cracked the same Indiana sample at $50{ }^{\circ} \mathrm{C}$ during $1 \mathrm{hr}$, we could observe in the thin sections the extensive amount of microcracks that developed in the homogeneous calcitic cement (Figures $2 \mathrm{j}$ and 2k), and we did not observe much cracks developing in the microporous areas. Thermally induced cracking occurs when the stress exceeds the local strength of the rock (Lu \& Jackson, 1996; Mallet et al., 2013, $2015 ; 2011)$. Different mechanisms can lead to such stress concentration. In polymineralic rocks, such as granites, each mineral possesses a different thermal expansion coefficient. This induces a thermal expansion mismatch (Fredrich \& Wong, 1986) and create high local stresses. The thermal expansion anisotropy of a mineral can also induce microcracks in a monomineralic rock, and calcite is known to possess such characteristic (Fredrich \& Wong, 1986; Lu \& Jackson, 1996). In addition to the previous mechanisms, one other factor that has to be taken into account is texture (Homand-Etienne \& Troalen, 1984). Several studies, on rocks or ceramics, showed that thermal cracking can be grain-size dependent and that a minimal grain-size is required (Evans, 1978; Fredrich \& Wong, 1986; Laws \& Lee, 1989). Therefore, the thermal behavior of monomineralic carbonate rocks might be conditioned by textural heterogeneity and thermal expansion anisotropy.

In a study by Lion et al. (2005), an oolitic limestone from Anstrude, France, has been subjected to thermal heating up $250{ }^{\circ} \mathrm{C}$ to study the effects on the hydraulic and poroelastic properties. However, not much thermally induced cracks were observed in the SEM photomicrographs, which might be explained by an insufficient temperature increase. Fredrich and Wong (1986) heated an Oakhall oolitic limestone at least up to $500^{\circ} \mathrm{C}$ to observe some microcracks. The general consensus between these studies is that monomineralic limestones with heterogeneous textures, such as oolitic limestones, are not very sensitive to thermal heating when compared to homogeneous textures or polymineralic rocks. In our study case, $500{ }^{\circ} \mathrm{C}$ was sufficient to create microcracks in the blocky cement of the Indiana limestone, but no cracking was observed in the grains composed of micrite. This is in agreement with the previous conclusion, as the micritic heterogeneous texture of the bioclasts may prevent the development of microcracks with temperature.

\subsection{Link Between Squirt Flow and Pore Type?}

For all the samples, the drained/undrained transitions were perfectly characterized and were in general agreement with Biot-Gassmann predictions, either for the bulk modulus or the shear modulus measurements, and in agreement with the predicted cutoff frequency $f_{1}^{*}=4 \kappa K_{d} / \eta L^{2}$. In laboratory measurements, characterizing this transition proved to be essential to distinguish the drained and undrained regimes from any other potential unrelaxed regime. Although we present here a limited number of samples, we can point out observations that may link squirt flow in carbonates to specific pore types.

The results of the intact Indiana, and Rustrel samples, demonstrate that intragranular microporosity alone cannot generate substantial squirt flow, even if the moduli are pressure-dependent suggesting crack closure. A previous study from Borgomano et al. (2017) showed that a dual-porosity oolitic limestone, with essentially intragranular microporosity and intergranular macroporosity, did not show any squirt flow dispersion either. A thermal treatment generating a substantial amount of cracks in the intergranular cement was necessary to observe squirt flow dispersion in the Indiana limestone, which interestingly affects principally the seismic frequency range. For the previous samples except the coquina limestone, no squirt flow can be expected above a differential pressure of $20 \mathrm{MPa}$ as all the cracks seem to be closed (Figure 11).

On the other hand, the coquina sample presented some strong dispersion in the sonic frequency rang, even at high differential pressure (Figure 11a), interpreted as squirt flow that would affect both the $P$ and the $S$ wave velocities in the field. Similarly to sandstones (e.g., Pimienta et al., 2015a; Spencer, 1981), the grain contacts are susceptible to be responsible for this squirt flow. The clastic, compacted, and poorly cemented microstructure of the coquina may explain this analogy with sandstones, as the grain contacts may act as cracks, unlike the other more cemented limestones. One major difference with sandstones we can point out is that this squirt flow dispersion seemed to affect $K, E$ and $G$ but not $\nu$, suggesting that the $V_{P} / V_{S}$ ratio of the coquina would be constant during the related undrained/unrelaxed transition at sonic log frequencies. This contradicts the observation made by Pimienta, Fortin, and Guéguen (2016) in a Fontainebleau sandstone with large content of microcracks (i.e., grain contacts), where $v$ was shown to decrease with increasing frequency with squirt flow.

From an effective medium approach, the pressure dependence of $K$ was used to infer the crack density and characteristic aspect ratio using Morlier's method (Morlier, 1971). This method, based on Walsh (1965), was 
applied on the hydrostatic oscillations results in dry conditions and gave crack aspect ratios varying from $1.4 \times 10^{-4}$ to $2.8 \times 10^{-4}$ (Table 1 ). Squirt flow, observed essentially in the coquina and the thermally cracked Indiana samples, seems clearly associated to high crack densities. However, crack densities of 0.5 and 0.2 , respectively, for the Rustrel and intact Indiana are not negligible but seem not to generate squirt flow.

The characteristic crack aspect ratio $(\xi)$, based on effective medium theory with penny-shaped cracks was used to infer the potential squirt flow cutoff frequency $f_{2}^{*}$ (equation (6)) to be then compared to the experimental results. Interestingly, we observed a very good agreement for the thermally induced cracks in the Indiana sample (Figure 11d) and a relatively good agreement for the coquina sample (Figure 11a). For the Rustrel and the intact Indiana, there seems to be no dispersion at all within the vicinity of the predicted cutoff frequencies although the velocities do show some pressure-dependence. Models using penny-shaped cracks may have to be used with caution for some carbonates.

The cutoff frequency $f_{2}^{*}$, defined in equation (6), applies for the micromechanical model commonly used for squirt flow, where penny-shaped cracks diffuse fluid radially into stiff pores (Gurevich et al., 2010; Murphy et al., 1986). Although this seems to be suited to model, both mechanically and hydraulically, grain contacts or cracks in homogeneous crystals (coquina and cracked Indiana), it may not represent the fluid diffusion that occurs in heterogeneous textures like micritized grains (Rustrel and intact Indiana). If microporosity is present along the crack's surfaces, we could speculate that the fluid diffusion may follow a "leak-off" mechanism rather than a radial flow, similarly to what occurs at larger scale between a fracture and the rock's porosity. The characteristic diffusion length of such leak off would be much smaller than for a fully radial flow, increasing the related cutoff frequency to higher frequencies.

\section{Conclusion}

The forced-oscillation method allowed to monitor the evolution of the dynamic moduli of fully saturated carbonate rocks over a very broad frequency range, in an attempt to cover seismic $(100 \mathrm{~Hz})$ and sonic log $(10 \mathrm{kHz})$ frequencies. This method, in combination with ultrasonic measurements $(1 \mathrm{MHz})$, proved to be essential to identify the different fluid-flow regimes and their impact on the wave velocities. Using both hydrostatic- and axial-stress oscillations on isotropic samples enabled us to infer all the dynamic moduli dispersion and attenuation and convert them to equivalent velocities.

The selected carbonate samples were very different in terms of microstructure, allowing for some correlation between characteristic pore types and potential dispersion in the field. The dispersion and attenuation observed in the measurements were all interpreted in terms of transitions between the drained, undrained, and unrelaxed fluid-flow regimes.

Measuring dry, drained, and undrained properties in a single experiment allows to compare the measurements to Biot-Gassmann's theory. For all our samples, Biot-Gassmann predictions of the undrained moduli were generally consistent with the measurements, and the cutoff frequency of the drained/undrained transition can be reliably predicted from the permeability measurements and the sample's length. Although this mechanism related to a global flow with the boundaries is an effect of the experimental setup, it is nevertheless a poroelastic mechanism that can be treated within the framework of linear viscoelasticity. Most importantly, it should not be confused for any other type of mechanism in laboratory measurements. In the field, the drained/undrained would be shifted to much lower frequencies due to the increase of the diffusion length.

In general, for the seismic frequencies, the dynamic moduli in fully saturated conditions were consistent with Biot-Gassmann. However, we showed that by intensively cracking intergranular cement of an Indiana grainstone by heat treatment, some strong squirt flow dispersion may affect the seismic frequencies. The coquina sample that presented a detritic-type of microstructure comparable to sandstones presented strong squirt flow dispersion in the sonic log frequency range. Similarly to sandstones, the grain to grain contacts may induce substantial squirt flow in these frequency ranges, with strong attenuation. On the other hand, intragranular microporosity does not generate much squirt flow dispersion that would affect field or ultrasonic measurements. The above conclusions should be taken into account when investigating carbonate-rich areas at the field scale. 
Acknowledgments

This work has been supported by TOTAL, under Project FR00007429. We would like to thank J. B. Regnet and M. Pellerin for providing the coquina sample, and D. Baden for the Rustrel sample. We also thank D. Deldique for the SEM analysis. We would like to thank TOTAL for allowing publication of these results. Finally, we would like to thank J. Dvorkin, G. Vasquez and an anonymous reviewer for their constructive comments. Data sets may be found online (at https://zenodo.org/ record/3529304).

\section{References}

Adam, L., Batzle, M., \& Brevik, I. (2006). Gassmann's fluid substitution and shear modulus variability in carbonates at laboratory seismic and ultrasonic frequencies. Geophysics, 71(6), F173-F183. https://doi.org/10.1190/1.2358494

Adam, L., Batzle, M., Lewallen, K. T., \& van Wijk, K. (2009). Seismic wave attenuation in carbonates. Journal of Geophysical Research, 114 B06208. https://doi.org/10.1029/2008JB005890

Adelinet, M., Fortin, J., \& Guéguen, Y. (2011). Dispersion of elastic moduli in a porous-cracked rock: Theoretical predictions for squirt-flow. Tectonophysics, 503(1-2), 173-181. https://doi.org/10.1016/j.tecto.2010.10.012

Adelinet, M., Fortin, J., Guéguen, Y., Schubnel, A., \& Geoffroy, L. (2010). Frequency and fluid effects on elastic properties of basalt: Experimental investigations. Geophysical Research Letters, 37, L02303. https://doi.org/10.1029/2009GL041660

Alsharhan, A. S., \& Nairn, A. E. M. (1997). Sedimentary basins and petroleum geology of the Middle East. Amsterdam: Elsevier.

Anderson, J. E., Cartwright, J., Drysdall, S. J., \& Vivian, N. (2000). Controls on turbidite sand deposition during gravity-driven extension of a passive margin: Examples from Miocene sediments in Block 4, Angola. Marine and Petroleum Geology, 17(10), 1165-1203. Retrieved from, http://www.sciencedirect.com/science/article/pii/S0264817200000593

Anselmetti, F. S., \& Eberli, G. P. (1993). Controls on sonic velocity in carbonates. Pure and Applied Geophysics, 141(2-4), 287-323. https:// doi.org/10.1007/BF00998333

Avseth, P., Mukerji, T., Mavko, G., \& Interpretation, Q. S. (2005). Quantitative seismic interpretation: Applying rock physics tools to reduce interpretation risk. Cambridge: Cambridge University Press. Retrieved from https://books.google.fr/books?id=S2boRYcDEZIC

Baechle, G. T., Eberli, G. P., Weger, R. J., \& Massaferro, J. L. (2009). Changes in dynamic shear moduli of carbonate rocks with fluid substitution. Geophysics, 74(3), E135-E147. https://doi.org/10.1190/1.3111063

Batzle, M. L., Han, D.-H., \& Hofmann, R. (2006). Fluid mobility and frequency-dependent seismic velocity—Direct measurements. Geophysics, 71(1), N1-N9. https://doi.org/10.1190/1.2159053

Bemer, E., Nguyen, M., Dautriat, J., Adelinet, M., Fleury, M., \& Youssef, S. (2016). Impact of chemical alteration on the poromechanical properties of carbonate rocks. Geophysical Prospecting, 64(4), 810-827. https://doi.org/10.1111/1365-2478.12387

Biot, M. A. (1956). Theory of propagation of elastic waves in a fluid-saturated porous solid. I. Low-frequency range. The Journal of the Acoustical Society of America, 28(2), 168-178. https://doi.org/10.1121/1.1908239

Borgomano, J., Masse, J.-P., \& Al Maskiry, S. (2002). The lower Aptian Shuaiba carbonate outcrops in Jebel Akhdar, northern Oman: Impact on static modeling for Shuaiba petroleum reservoirs. AAPG bulletin, 86(9), 1513-1529. https://doi.org/10.1306/ 61EEDCE2-173E-11D7-8645000102C1865D

Borgomano, J., Masse, J.-P., Fenerci-Masse, M., \& Fournier, F. (2013). Petrophysics of Lower Cretaceous platform carbonate outcrops in Provence (SE France): Implications for carbonate reservoir characterisation. Journal of Petroleum Geology, 36(1), 5-41. https://doi.org/ 10.1111/jpg.12540/full

Borgomano, J. V. M., Pimienta, L., Fortin, J., \& Guéguen, Y. (2017). Dispersion and attenuation measurements of the elastic moduli of a dual-porosity limestone. Journal of Geophysical Research: Solid Earth, 122, 2690-2711. https://doi.org/10.1002/2016JB013816

Brace, W. F., \& Riley, D. K. (1972). Static uniaxial deformation of 15 rocks to $30 \mathrm{~kb}$. International Journal of Rock Mechanics and Mining Sciences \& Geomechanics Abstracts, 9(2), 271-288. https://doi.org/10.1016/0148-9062(72)90028-9

Castagna, J. P., Sun, S., \& Siegfried, R. W. (2003). Instantaneous spectral analysis: Detection of low-frequency shadows associated with hydrocarbons. The Leading Edge, 22(2), 120-127. https://doi.org/10.1190/1.1559038

Chapman, S., Borgomano, J. V. M., Yin, H., Fortin, J., \& Quintal, B. (2019). Forced oscillation measurements of seismic wave attenuation and stiffness moduli dispersion in glycerine-saturated Berea sandstone. Geophysical Prospecting, 67(4), 956-968. https://doi.org/10.1111/ 1365-2478.12710

Chapman, M., Liu, E., \& Li, X.-Y. (2006). The influence of fluid sensitive dispersion and attenuation on AVO analysis. Geophysical Journal International, 167(1), 89-105. https://doi.org/10.1111/j.1365-246X.2006.02919.X

Chapman, S., Tisato, N., Quintal, B., \& Holliger, K. (2016). Seismic attenuation in partially saturated Berea sandstone submitted to a range of confining pressures. Journal of Geophysical Research: Solid Earth, 121, 1664-1676. https://doi.org/10.1002/2015JB012575

Cheng, C., ToksSz, M., \& Willis, M. (1984). Reply to the comment on "Determination of in situ attenuation from full waveform acoustic logs". Journal of Geophysical Research, 89, 3400-3402.

Cheng, C., ToksöPz, M. N., \& Willis, M. E. (1982). Determination of in situ attenuation from full waveform acoustic logs. Journal of Geophysical Research, 87(B7), 5477-5484. https://doi.org/10.1029/JB087iB07p05477

David, E. C., Fortin, J., Schubnel, A., Guéguen, Y., \& Zimmerman, R. W. (2013). Laboratory measurements of low-and high-frequency elastic moduli in Fontainebleau sandstone. Geophysics, 78(5), D369-D379. https://doi.org/10.1190/geo2013-0070.1

Dvorkin, J., Mavko, G., \& Nur, A. (1995). Squirt flow in fully saturated rocks. Geophysics, 60(1), 97-107. https://doi.org/10.1190/1.1443767

Eberli, G. P., Baechle, G. T., Anselmetti, F. S., \& Incze, M. L. (2003). Factors controlling elastic properties in carbonate sediments and rocks. The Leading Edge, 22(7), 654-660. https://doi.org/10.1190/1.1599691

Evans, A. G. (1978). Microfracture from thermal expansion anisotropy-I. Single phase systems. Acta Metallurgica, 26(12), 1845-1853. https://doi.org/10.1016/0001-6160(78)90097-4

Fabricius, I. L., Bächle, G. T., \& Eberli, G. P. (2010). Elastic moduli of dry and water-saturated carbonates-Effect of depositional texture, porosity, and permeability. Geophysics, 75(3), N65-N78. https://doi.org/10.1190/1.3374690

Fossum, A. F., Senseny, P. E., Pfeifle, T. W., \& Mellegard, K. D. (1995). Experimental determination of probability distributions for parameters of a Salem limestone cap plasticity model. Mechanics of Materials, 21(2), 119-137. Retrieved from http://www.sciencedirect.com/ science/article/pii/016766369500002X

Fournier, F., \& Borgomano, J. (2009). Critical porosity and elastic properties of microporous mixed carbonate-siliciclastic rocks. Geophysics, 74(2), E93-E109. https://doi.org/10.1190/1.3043727

Fournier, F., Leonide, P., Biscarrat, K., Gallois, A., Borgomano, J., \& Foubert, A. (2011). Elastic properties of microporous cemented grainstones. Geophysics, 76(6), E211-E226. https://doi.org/10.1190/geo2011-0047.1

Fournier, F., Léonide, P., Kleipool, L., Toullec, R., Reijmer, J. J., Borgomano, J., et al. (2014). Pore space evolution and elastic properties of platform carbonates (Urgonian limestone, Barremian-Aptian, SE France). Sedimentary Geology, 308, 1-17. http://www.sciencedirect. com/science/article/pii/S0037073814000840

Frazer, L. N., Sun, X., \& Wilkens, R. H. (1997). Changes in attenuation with depth in an ocean carbonate section: Ocean Drilling Program Sites 806 and 807, Ontong Java Plateau. Journal of Geophysical Research, 102(B2), 2983-2997. https://doi.org/10.1029/96JB03189

Fredrich, J. T., \& Wong, T.-f. (1986). Micromechanics of thermally induced cracking in three crustal rocks. Journal of Geophysical Research, 91(B12), 12,743-12,764. https://doi.org/10.1029/JB091iB12p12743 
Gassmann, F. (1951). Elasticity of porous media. Vierteljahrsschrder Naturforschenden Gesselschaft, 96, 1-23. Retrieved from http:// citeseerx.ist.psu.edu/viewdoc/download?doi=10.1.1.48.9319\&rep=rep1\&type $=$ pdf

Gurevich, B., Makarynska, D., de Paula, O. B., \& Pervukhina, M. (2010). A simple model for squirt-flow dispersion and attenuation in fluid-saturated granular rocks. Geophysics, 75(6), N109-N120. https://doi.org/10.1190/1.3509782

Hart, D. J., \& Wang, H. F. (1995). Laboratory measurements of a complete set of poroelastic moduli for Berea sandstone and Indiana limestone. Journal of Geophysical Research, 100(B9), 17,741-17,751.

Homand-Etienne, F., \& Troalen, J.-P. (1984). Behaviour of granites and limestones subjected to slow and homogeneous temperature changes. Engineering Geology, 20(3), 219-233. https://doi.org/10.1016/0013-7952(84)90002-4

Jackson, I., Schijns, H., Schmitt, D. R., Mu, J., \& Delmenico, A. (2011). A versatile facility for laboratory studies of viscoelastic and poroelastic behaviour of rocks. Review of Scientific Instruments, 82(6), 064501. https://doi.org/10.1063/1.3592154

Jaeger, J. C., Cook, N. G., \& Zimmerman, R. (2009). Fundamentals of rock mechanics. Malden, MA: John Wiley \& Sons.

Ji, Y., Baud, P., Vajdova, V., \& Wong, T.-f. (2012). Characterization of pore geometry of Indiana limestone in relation to mechanical compaction. Oil \& Gas Science and Technology - Revue d'IFP Energies nouvelles, 67(5), 753-775. https://doi.org/10.2516/ogst/2012051

Johnston, D. H., \& Toksöz, M. N. (1980). Thermal cracking and amplitude dependent attenuation. Journal of Geophysical Research, 85(B2), 937-942. https://doi.org/10.1029/JB085iB02p00937

Laws, N., \& Lee, J. C. (1989). Microcracking in polycrystalline ceramics: Elastic isotropy and thermal anisotropy. Journal of the Mechanics and Physics of Solids, 37(5), 603-618. https://doi.org/10.1016/0022-5096(89)90031-8

Léonide, P., Borgomano, J., Masse, J.-P., \& Doublet, S. (2012). Relation between stratigraphic architecture and multi-scale heterogeneities in carbonate platforms: The Barremian-lower Aptian of the Monts de Vaucluse, SE France. Sedimentary Geology, 265-266, 87-109. https:// doi.org/10.1016/j.sedgeo.2012.03.019

Léonide, P., Fournier, F., Reijmer, J. J., Vonhof, H., Borgomano, J., Dijk, J., et al. (2014). Diagenetic patterns and pore space distribution along a platform to outer-shelf transect (Urgonian limestone, Barremian-Aptian, SE France). Sedimentary Geology, 306, 1-23. https:// doi.org/10.1016/j.sedgeo.2014.03.001

Lion, M., Skoczylas, F., \& Ledésert, B. (2005). Effects of heating on the hydraulic and poroelastic properties of Bourgogne limestone International Journal of Rock Mechanics and Mining Sciences, 42(4), 508-520. https://doi.org/10.1016/j.ijrmms.2005.01.005

Lu, C., \& Jackson, I. (1996). Seismic-frequency laboratory measurements of shear mode viscoelasticity in crustal rocks I: Competition between cracking and plastic flow in thermally cycled Carrara marble. Physics of the earth and planetary interiors, 94(1-2), 105-119. http://www.sciencedirect.com/science/article/pii/0031920195030794

Lucia, F. J. (1995). Rock-fabric/petrophysical classification of carbonate pore space for reservoir characterization. AAPG Bulletin, 79(9), $1275-1300$.

Madonna, C., \& Tisato, N. (2013). A new seismic wave attenuation module to experimentally measure low-frequency attenuation in extensional mode. Geophysical Prospecting, 61(2), 302-314. https://doi.org/10.1111/1365-2478.12015/full

Mallet, C., Fortin, J., Guéguen, Y., \& Bouyer, F. (2013). Effective elastic properties of cracked solids: An experimental investigation. International Journal of Fracture, 182(2), 275-282.

Mallet, C., Fortin, J., Guéguen, Y., \& Bouyer, F. (2015). Brittle creep and subcritical crack propagation in glass submitted to triaxial conditions. Journal of Geophysical Research: Solid Earth, 120, 879-893. https://doi.org/10.1002/2014JB011231

Marton, L. G., Tari, G. C., \& Lehmann, C. T. (2000). Evolution of the Angolan passive margin, West Africa, with emphasis on post-salt structural styles. Atlantic Rifts and Continental <argins, 115, 129-149. https://doi.org/10.1029/GM115p0129

Mavko, G., \& Jizba, D. (1991). Estimating grain-scale fluid effects on velocity dispersion in rocks. Geophysics, 56(12), 1940-1949. https:// doi.org/10.1190/1.1443005

Mavko, G., Mukerji, T., \& Dvorkin, J. (2009). The rock physics handbook: Tools for seismic analysis of porous media. Cambridge: Cambridge university press.

Mavko, G., \& Nur, A. (1975). Melt squirt in the asthenosphere. Journal of Geophysical Research, 80(11), 1444-1448.

Michalopoulos, L. P., \& Triandafilidis, G. E. (1976). Influence of water on hardness, strength and compressibility of rock. BULL ASSOC ENG GEOL, xiii(1), 1-22. https://doi.org/10.2113/gseegeosci.xiii.1.1

Mikhaltsevitch, V., Lebedev, M., \& Gurevich, B. (2014). A laboratory study of low-frequency wave dispersion and attenuation in water-saturated sandstones. The Leading Edge, 33(6), 616-622.

Mikhaltsevitch, V., Lebedev, M., \& Gurevich, B. (2016a). Laboratory measurements of the effect of fluid saturation on elastic properties of carbonates at seismic frequencies: Effect of fluid saturation on carbonates. Geophysical Prospecting, 64(4), 799-809. https://doi.org/10. $1111 / 1365-2478.12404$

Mikhaltsevitch, V., Lebedev, M., \& Gurevich, B. (2016b). Validation of the laboratory measurements at seismic frequencies using the Kramers-Kronig relationship. Geophysical Research Letters, 43, 4986-4991. https://doi.org/10.1002/2016GL069269

Morlier, P. (1971). Description de l'etat de fissuration d'une roche a partir d'essais non-destructifs simples. Rock Mechanics and Rock Engineering, 3(3), 125-138. http://www.springerlink.com/index/K12157L2U1679831.pdf

Müller, T. M., Gurevich, B., \& Lebedev, M. (2010). Seismic wave attenuation and dispersion resulting from wave-induced flow in porous rocks-A review. Geophysics, 75(5), 75A147-75A164. https://doi.org/10.1190/1.3463417

Murphy, W. F. III, Winkler, K. W., \& Kleinberg, R. L. (1986). Acoustic relaxation in sedimentary rocks: Dependence on grain contacts and fluid saturation. Geophysics, 51(3), 757-766.

O'Connell, R. J., \& Budiansky, B. (1977). Viscoelastic properties of fluid-saturated cracked solids. Journal of Geophysical Research, 82(36), 5719-5735. https://doi.org/10.1029/GL005i001p00005

O'Connell, R. J., \& Budiansky, B. (1978). Measures of dissipation in viscoelastic media. Geophysical Research Letters, 5(1), 5-8. https://doi. org/10.1029/GL005i001p00005

Odebeatu, E., Zhang, J., Chapman, M., Liu, E., \& Li, X.-Y. (2006). Application of spectral decomposition to detection of dispersion anomalies associated with gas saturation. The Leading Edge, 25(2), 206-210. https://doi.org/10.1190/1.2172314

Ougier-Simonin, A., Guéguen, Y., Fortin, J., Schubnel, A., \& Bouyer, F. (2011). Permeability and elastic properties of cracked glass under pressure. Journal of Geophysical Research, 116, B07203. https://doi.org/10.1029/2010JB008077

Paffenholz, J., \& Burkhardt, H. (1989). Absorption and modulus measurements in the seismic frequency and strain range on partially saturated sedimentary rocks. Journal of Geophysical Research, 7, 9493-9507.

Pimienta, L., Borgomano, J. V. M., Fortin, J., \& Guéguen, Y. (2017). Elastic dispersion and attenuation in fully saturated sandstones: Role of mineral content, porosity, and pressures. Journal of Geophysical Research: Solid Earth, 122, 9950-9965. https://doi.org/10.1002/ 2017JB014645

Pimienta, L., Borgomano, J. V. M., Fortin, J., \& Guéguen, Y. (2016). Modelling the drained/undrained transition: Effect of the measuring method and the boundary conditions. Geophysical Prospecting, 64(4), 1098-1111. https://doi.org/10.1111/1365-2478.12390 
Pimienta, L., Fortin, J., \& Guéguen, Y. (2015a). Bulk modulus dispersion and attenuation in sandstones. Geophysics, 80(2), D111-D127. https://doi.org/10.1190/geo2014-0335.1

Pimienta, L., Fortin, J., \& Guéguen, Y. (2015b). Experimental study of Young's modulus dispersion and attenuation in fully saturated sandstones. Geophysics, 80(5), L57-L72. https://doi.org/10.1190/geo2014-0532.1

Pimienta, L., Fortin, J., \& Guéguen, Y. (2016). Effect of fluids and frequencies on Poisson's ratio of sandstone samples. Geophysics, 81(2), D183-D195. https://doi.org/10.1190/geo2015-0310.1

Regnet, J.-B., Fortin, J., Nicolas, A., Pellerin, M., \& Gueguen, Y. (2018). Elastic properties of continental carbonates: From controlling factors to an applicable model for acoustic velocity predictions. Geophysics, 84(1), MR45-MR59. https://doi.org/10.1190/geo2017-0344.1

Rice, J. R., \& Cleary, M. P. (1976). Some basic stress diffusion solutions for fluid-saturated elastic porous media with compressible constituents. Reviews of Geophysics, 14(2), 227-241.

Rodriguez-Navarro, C., Ruiz-Agudo, E., Luque, A., Rodriguez-Navarro, A. B., \& Ortega-Huertas, M. (2009). Thermal decomposition of calcite: Mechanisms of formation and textural evolution of CaO nanocrystals. American Mineralogist, 94(4), 578-593. https://doi.org/ 10.2138/am.2009.3021

Sarout, J. (2012). Impact of pore space topology on permeability, cut-off frequencies and validity of wave propagation theories: Pore space topology and wave propagation. Geophysical Journal International, 189(1), 481-492. https://doi.org/10.1111/j.1365-246X.2011.05329.x

Savoye, B., Babonneau, N., Dennielou, B., \& Bez, M. (2009). Geological overview of the Angola-Congo margin, the Congo deep-sea fan and its submarine valleys. Deep Sea Research Part II: Topical Studies in Oceanography, 56(23), 2169-2182. https://doi.org/10.1016/j.dsr2. 2009.04.001

Sidler, R., Rubino, J. G., \& Holliger, K. (2013). Quantitative comparison between simulations of seismic wave propagation in heterogeneous poro-elastic media and equivalent visco-elastic solids for marine-type environments. Geophysical Journal International, 193(1), 463-474.

Solazzi, S. G., Rubino, J. G., Müller, T. M., Milani, M., Guarracino, L., \& Holliger, K. (2016). An energy-based approach to estimate seismic attenuation due to wave-induced fluid flow in heterogeneous poroelastic media. Geophysical Supplements to the Monthly Notices of the Royal Astronomical Society, 207(2), 823-832.

Spencer, J. W. (1981). Stress relations at low frequencies in fluid saturated rocks: Attenuation and modulus dispersion. Journal of Geophysical Research, 86(80), 1803-1812.

Spencer, J. W., \& Shine, J. (2016). Seismic wave attenuation and modulus dispersion in sandstones. Geophysics, 81(3), D211-D231. https:// doi.org/10.1190/geo2015-0342.1

Subramaniyan, S., Quintal, B., Madonna, C., \& Saenger, E. H. (2015). Laboratory-based seismic attenuation in Fontainebleau sandstone: Evidence of squirt flow. Journal of Geophysical Research: Solid Earth, 120, 7526-7535. https://doi.org/10.1002/2015JB012290

Subramaniyan, S., Quintal, B., \& Saenger, E. H. (2017). Forced oscillation measurements of seismic attenuation in fluid saturated sandstone. Acta Geophysica, 65(1), 165-172.

Sun, X., \& Frazer, L. N. (2000). Shear wave attenuation profile from sonic dipole well-log data. Geophysical Research Letters, 27(2), $285-288$. https://doi.org/10.1029/1999GL005423

Sun, C., Tang, G., Zhao, J., Zhao, L., \& Wang, S. (2018). An enhanced broad-frequency-band apparatus for dynamic measurement of elastic moduli and Poisson's ratio of rock samples. Review of Scientific Instruments, 89(6), 064503. https://doi.org/10.1063/1.5018152

Szewczyk, D., Bauer, A., \& Holt, R. M. (2016). A new laboratory apparatus for the measurement of seismic dispersion under deviatoric stress conditions: Apparatus for seismic dispersion. Geophysical Prospecting, 64(4), 789-798. https://doi.org/10.1111/1365-2478.12425

Thompson, D. L., Stilwell, J. D., \& Hall, M. (2015). Lacustrine carbonate reservoirs from Early Cretaceous rift lakes of Western Gondwana: Pre-Salt coquinas of Brazil and West Africa. Gondwana Research, 28(1), 26-51. http://linkinghub.elsevier.com/retrieve/pii/ S1342937X15000027

Tisato, N., \& Madonna, C. (2012). Attenuation at low seismic frequencies in partially saturated rocks: Measurements and description of a new apparatus. Journal of Applied Geophysics, 86, 44-53. https://doi.org/10.1016/j.jappgeo.2012.07.008

Tisato, N., Quintal, B., Chapman, S., Podladchikov, Y., \& Burg, J.-P. (2015). Bubbles attenuate elastic waves at seismic frequencies: First experimental evidence. Geophysical Research Letters, 42, 3880-3887. https://doi.org/10.1002/2015GL063538

Vajdova, V., Baud, P., \& Wong, T.-f. (2004). Compaction, dilatancy, and failure in porous carbonate rocks. Journal of Geophysical Research, 109, B05204. https://doi.org/10.1029/2003JB002508

Verwer, K., Eberli, G., Baechle, G., \& Weger, R. (2010). Effect of carbonate pore structure on dynamic shear moduli. Geophysics, 75(1), E1-E8. https://doi.org/10.1190/1.3280225

Walsh, J. B. (1965). The effect of cracks on the compressibility of rocks. Journal of Geophysical Research, 70(2), 381-389. https://doi.org/10. 1029/JZ070i002p00381

Winkler, K. (1985). Dispersion analysis of velocity and attenuation in Berea sandstone. Journal of Geophysical Research, 90(6), 793-6.

Wonham, J. P., Cyrot, M., Nguyen, T., Louhouamou, J., \& Ruau, O. (2010). Integrated approach to geomodelling and dynamic simulation in a complex mixed siliciclastic-carbonate reservoir, N'Kossa field, Offshore Congo. Geological Society, London, Special Publications, 347(1), 133-163. https://doi.org/10.1144/SP347.10

Yin, H., Borgomano, J. V. M., Wang, S., Tiennot, M., Fortin, J., \& Guéguen, Y. (2019). Fluid substitution and shear weakening in clay-bearing sandstone at seismic frequencies. Journal of Geophysical Research: Solid Earth, 124, 1254-1272. https://doi.org/10.1029/2018JB016241

Yin, H., Zhao, J., Tang, G., Zhao, L., Ma, X., \& Wang, S. (2017). Pressure and fluid effect on frequency-dependent elastic moduli in fully saturated tight sandstone. Journal of Geophysical Research: Solid Earth, 122, 8925-8942. https://doi.org/10.1002/2017JB014244

Zhu, W., Baud, P., \& Wong, T.-f. (2010). Micromechanics of cataclastic pore collapse in limestone. Journal of Geophysical Research: Solid Earth, 115, B04405. https://doi.org/10.1029/2009JB006610 